\title{
Sequential Maturation of Olfactory Sensory Neurons in the Mature Olfactory Epithelium
}

\author{
Teresa Liberia,, ${ }^{1,2}$ Eduardo Martin-Lopez, ${ }^{1,2}$ Sarah J. Meller, ${ }^{1,2,3}$ and ${ }^{\mathbb{C}}$ Charles A. Greer ${ }^{1,2,3}$
}

https://doi.org/10.1523/ENEURO.0266-19.2019

${ }^{1}$ Department of Neuroscience, Yale University School of Medicine, New Haven, Connecticut 06520, ${ }^{2}$ Department of Neurosurgery, Yale University School of Medicine, New Haven, Connecticut 06520, and ${ }^{3}$ The Interdepartmental Neuroscience Graduate Program, Yale University School of Medicine, New Haven, Connecticut 06520

\begin{abstract}
The formation of the olfactory nerve and olfactory bulb (OB) glomeruli begins embryonically in mice. However, the development of the olfactory system continues throughout life with the addition of new olfactory sensory neurons (OSNs) in the olfactory epithelium (OE). Much attention has been given to the perinatal innervation of the OB by OSN axons, but in the young adult the process of OSN maturation and axon targeting to the OB remains controversial. To address this gap in understanding, we used BrdU to label late-born OSNs in young adult mice at postnatal day 25 (P25-born OSNs) and timed their molecular maturation following basal cell division. We show that OSNs in young adults undergo a sequential molecular development with the expression of GAP 43 (growth-associated protein 43) > AC3 (adenylyl cyclase 3) > OMP (olfactory marker protein), consecutively, in a time frame of $\sim 8 \mathrm{~d}$. To assess OSN axon development, we implemented an in vivo fate-mapping strategy to label P25-born OSNs with ZsGreen. Using sampling intervals of $24 \mathrm{~h}$, we demonstrate the progressive extension of OSN axons in the OE, through the foramen of the cribriform plate, and onto the surface of the OB. OSN axons reached the $\mathrm{OB}$ and began to target and robustly innervate specific glomeruli $\sim 10 \mathrm{~d}$ following basal cell division, a time point at which OMP expression becomes evident. Our data demonstrate a sequential process of correlated axon extension and molecular maturation that is similar to that seen in the neonate, but on a slightly longer timescale and with regional differences in the OE.
\end{abstract}

Key words: maturation; neurogenesis; olfactory epithelium; olfactory sensory neuron; olfactory system

\section{Significance Statement}

The ability to navigate using odor cues is in part dependent on the highly organized topographic map established between the olfactory epithelium and the olfactory bulb. The maintenance of this precise organization entails a challenge, since olfactory sensory neurons in the olfactory epithelium are constantly replaced throughout life. This dynamic structure combined with a fate-mapping strategy offers the ideal model to study neuronal maturation and successful axon targeting in adult neurogenesis. Our findings shed new light on the dynamics and fate of adult-born olfactory sensory neurons, which have to negotiate an established and functional system while undergoing sequential maturation and extension of their axon in a fashion that grossly recapitulates the mechanisms observed in the perinatal stages.

\section{Introduction}

The olfactory epithelium (OE) is a pseudostratified columnar epithelium with three multicellular compartments

Received July 9, 2019; accepted September 18, 2019; First published September 25, 2019.

The authors declare no competing financial interests. (for review, see Sokpor et al., 2018). Progenitor cells are proximal to the basal lamina, and generate new olfactory sensory neurons (OSNs). The intermediate layer includes 
OSNs in different stages of differentiation. Immature OSNs (iOSNs) are located deeper in the intermediate zone, proximal to the stem cells, while mature OSNs (mOSNs) are found superficially, proximal to the lumen of the nasal cavity. The mOSNs extend an apical dendrite to the OE lumen, where it enlarges to form a dendritic knob from which 8-15 cilia extend and spread across the OE surface. OSNs are organized throughout the entire OE in overlapping domains according to the odor receptor (OR) they express (Ressler et al., 1993; Vassar et al., 1993; Sullivan et al., 1996; Miyamichi et al., 2005). Finally, the most apical layer of the epithelium includes non-neuronal (supporting) cells such as sustentacular cells (SUSs), microvillar cells, and the ducts of Bowman's glands (Schwob et al., 2017).

The OE of juvenile mice includes $\sim 5,200,000$ OSNs on each side of the nose (Kawagishi et al., 2014; Bressel et al., 2016), each of which expresses only 1 of $\sim 1200$ candidate ORs (Monahan and Lomvardas, 2015). OSN axons selectively target approximately two to three glomeruli in the ipsilateral olfactory bulb (OB) based in part on the ORs that these cells express (Richard et al., 2010). OSN neurogenesis is robust throughout life (Graziadei and Graziadei, 1979; Graziadei and Monti Graziadei, 1985; Schwob, 2002; Iwema et al., 2004). This presents a challenge for the precise innervation of the glomeruli by OSN axons, as the topography of glomeruli targeting based on OR expression established during the embryonic development is maintained throughout life (Treloar et al., 2002; Cheung et al., 2014). The axons of new OSNs generated in the adult must navigate established axon tracts to innervate the appropriate glomerulus, a process that is not yet fully understood. Maintaining topography between the OSNs in the OE and their glomerular targets in the $\mathrm{OB}$, despite the continuous turnover of these cells, contributes to the stability of odor representation throughout life.

The OE is dynamic and develops throughout life, and may reach a point of equilibrium in which the OSN loss is counterbalanced by ongoing OSN neurogenesis. Our understanding of OSN neurogenesis has benefited from studies that have examined different aspects of the process, including OSN survival, regeneration, proliferation, and aging (Kondo et al., 2010; Holl, 2018; Ueha et al., 2018; Savya et al., 2019). Rodriguez-Gil et al. (2015) previously characterized the maturation of perinatally generated OSNs, a period of exuberant neurogenesis that occurs before the maturation of the olfactory pathway.

This work has been supported by National Institutes of Health Grants R01-DC-013791 and R01-DC-016851(to C.A.G.), and DOD-WA-1XWH-17-10564 (to C.A.G.); and a Yale University Brown-Coxe Fellowship (to T.L.).

Acknowledgments: We thank Dr. Diego J. Rodriguez-Gil for discussion; and Christine Kaliszewski and Dolores Montoya for assistance.

Correspondence should be addressed to Charles A. Greer at Charles.greer@yale.edu.

https://doi.org/10.1523/ENEURO.0266-19.2019

Copyright (C) 2019 Liberia et al.

This is an open-access article distributed under the terms of the Creative Commons Attribution 4.0 International license, which permits unrestricted use, distribution and reproduction in any medium provided that the original work is properly attributed.
However, little has been done to understand the behavior of OSNs produced in a mature environment, when the olfactory system is completely formed and there is less neuronal plasticity within the resulting circuits.

In this study, we analyze the molecular maturation and axon targeting of OSNs in the adolescent mouse. We show that while the sequence of OSN molecular development is similar in perinatal and adolescent mice, neurogenesis across the $\mathrm{OE}$ is regionally heterogeneous. Following neurogenesis, the radial maturation of OSNs in the $\mathrm{OE}$ and the expression of molecular markers indicative of stages of maturation are qualitatively comparable, but with quantitative differences. Similarly, the extension of axons to the OB is slower in young adult mice compared with perinatal mice. These new data are important for understanding the dynamics of adult neurogenesis and the challenges that newly born neurons face in incorporating into the $\mathrm{OE}$ and extending their axons to the $\mathrm{OB}$.

\section{Materials and Methods}

\section{Animals}

All experiments were conducted on mice produced by cross-mating Ascl1tm1.1 (Cre/ERT2)Jejo/J mice (stock \#012882, The Jackson Laboratory), maintained as heterozygous (Ascl1 ${ }^{\mathrm{CreERT} 2 /+}$ ), with B6.Cg-Gt(ROSA)26Sortm6 (CAG-ZsGreen1)Hze/J reporter mice (stock \#007906, The Jackson Laboratory). Littermates with $\mathrm{Ascl} 1^{+/+}$; R26R ${ }^{\text {ZsGreen }}$ genotype do not include the Ascl1-Cre/ERT2 allele and were used to assess neurogenesis rate, radial migration of OSNs, and molecular maturation. Littermates containing the Ascl1-Cre/ERT2 allele (Ascl1 ${ }^{\mathrm{CreERT} 2 /+}$; $\mathrm{R}^{26 \mathrm{R}^{\mathrm{ZsG}} \mathrm{seen}}$ ) were used for analyzing OSN axonal extension. In the presence of $4 \mathrm{OH}$-tamoxifen $(4 \mathrm{OH}-\mathrm{Tx})$, intermediate progenitor cells express the fluorescent protein ZsGreen, allowing us to trace their lineage. Although it is not an axonal marker, ZsGreen is a reporter protein ideally suited for whole-cell labeling, including cell body and all processes. The Ascl1 ${ }^{\text {CreERT2/+ }}$; R26R ${ }^{\text {ZsGreen }}$ mice will subsequently be referred as double transgenic mice. All experiments randomly included both male and female mice, although sex comparisons were not pursued. Mice were housed with a $12 \mathrm{~h}$ light/dark cycle with access to standard food and water ad libitum. All animal care and use were approved by the Yale University Animal Care and Use Committee.

\section{BrdU and $40 \mathrm{H}-\mathrm{Tx}$ administration}

For analysis of neurogenesis rate in the septal OE, Ascl1 ${ }^{+/+} ; \mathrm{R}_{26 \mathrm{R}^{Z s G r e e n}}$ mice were injected with $50 \mathrm{mg} / \mathrm{kg}$ thymidine analog BrdU (BD Pharmingen) twice, $2 \mathrm{~h}$ apart in mice at postnatal day $7(\mathrm{P} 7 ; n=8)$ and P25 $(n=6)$. Mice were killed and assessed at $7 \mathrm{~d}$ post-BrdU injection (DPI-B-7). To analyze OSN migration and maturation, mice with the Ascl1 ${ }^{+/+}$; R26R ${ }^{\text {ZsGreen }}$ genotype were separated into six groups $(n=3)$ and injected with $\mathrm{BrdU}(50$ $\mathrm{mg} / \mathrm{kg}$ ) twice, $2 \mathrm{~h}$ apart at $\mathrm{P} 25$. Tissues were collected at DPI-B-1, DPI-B-3, DPI-B-5, DPI-B-8, DPI-B-10, and DPI$\mathrm{B}-12$. For analysis of the OSN axon extension, we used Ascl1 ${ }^{\text {CreERT2/+; }}$ R26R ${ }^{\text {ZsGreen }}$ mice exclusively at P25. These animals were distributed in 10 groups $(n=3)$ and 
Table 1: Primary and secondary antibodies used in the study

\begin{tabular}{lllll}
\hline \multicolumn{1}{c}{ Anti } & Host & \multicolumn{1}{c}{ Isotype } & Dilution & \multicolumn{1}{c}{ Company (catalog \#) } \\
\hline Primary antibodies & & & & \\
AC3 & Rabbit & Polyclonal IgG & $1: 300$ & Thermo Fisher Scientific (PA5-35382) \\
BrdU & Rat & Monoclonal IgG & $1: 300$ & Abcam (ab6326) \\
BrdU & Rat & Monoclonal IgG & $1: 300$ & Accurate Chemical (OBT 0030) \\
cCasp3 & Rabbit & Polyclonal IgG & $1: 500$ & Cell Signaling Technology (9661) \\
GAP 43 & Rabbit & Polyclonal IgG & $1: 1000$ & Millipore-Chemicon (AB5220) \\
Ki67 & Rabbit & Polyclonal IgG & $1: 200$ & Novus (110-89719) \\
OMP & Goat & Polyclonal IgG & $1: 1000$ & Wako (544-10001) \\
ZsGreen & Rabbit & Polyclonal IgG & $1: 300$ & Clontech (632474) \\
\hline & & & & Company \\
Anti & Host & Label & Dilution & \\
\hline Secondary antibodies & & & Thermo Fisher Scientific \\
Goat & Donkey & A555 & $1: 1000$ & Thermo Fisher Scientific \\
Goat & Donkey & A647 & $1: 1000$ & Thermo Fisher Scientific \\
Rat & Donkey & A488 & $1: 1000$ & Thermo Fisher Scientific \\
Rabbit & Donkey & A488 & $1: 1000$ & Thermo Fisher Scientific \\
Rabbit & Donkey & A555 & $1: 1000$ & \\
\hline
\end{tabular}

injected with a single dose of $40 \mathrm{mg} / \mathrm{kg}$ 4OH-Tx (SigmaAldrich). Tissue was collected at 1, 2, 3, 4, 5, 6, 7, 8, 10, and $12 \mathrm{~d}$ post-4OH-Tx injection (DPI-Tx).

\section{Control experiments}

To test the accuracy of the $4 \mathrm{OH}-\mathrm{Tx}$-inducible Cre-LoxP system, we ran three control experiments. First, we injected one group of double transgenic mice (Ascl1 ${ }^{\text {CreERT2/+; }}$

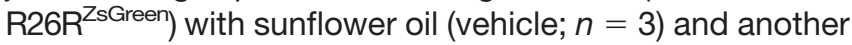
group with $4 \mathrm{OH}-\mathrm{Tx}(n=3)$. Double transgenic animals showed a considerable amount of ZsGreen ${ }^{+}$OSNs in the $\mathrm{OE}$ at $12 \mathrm{~d}$ following $4 \mathrm{OH}-\mathrm{Tx}$ injection (see Fig. 7B). However, we did not detect any specific ZsGreen ${ }^{+}$neurons at 12 d post-vehicle injection (DPI-vehicle-12; see Fig. 7C). Likewise, we injected a third group of $\mathrm{R}^{26 \mathrm{R}^{\mathrm{ZsGreen}}} \mathrm{Ascl}^{+/+}$reporter mice with $4 \mathrm{OH}-\mathrm{Tx}$, and at DPI-Tx-12 they did not show any ZsGreen ${ }^{+}$OSNs in the $\mathrm{OE}(n=3$; see Fig. 7D). Using these control experiments, we established that Cre enzyme only recombines and allows ZsGreen expression in the presence of both CreERT2 gene and 4OH-Tx.

\section{Tissue processing}

Briefly, mice were deeply anesthetized with an overdose of Euthasol (Virbac) and perfused transcardially with $0.9 \% \mathrm{NaCl}$ in $0.1 \mathrm{M} \mathrm{PBS}, \mathrm{pH} 7.4$ with 1 unit/ml heparin, followed by $4 \%$ paraformaldehyde (JT Baker) in PBS. Animals were decapitated, the skin was removed from the skull and, with the brain in situ, was postfixed in the same fixative solution for $2 \mathrm{~h}$ at $4^{\circ} \mathrm{C}$, transferred to PBS overnight, decalcified in EDTA for 7-10 d at $4 \mathrm{C}$ and embedded in OCT (optimal cutting temperature) compound (Thermo Fisher Scientific). Finally, $25 \mu \mathrm{m}$ sections, including the $\mathrm{OE}$ and $\mathrm{OB}$, were serially collected in the coronal and sagittal planes using a Reichert Frigocut Cryostat $\mathrm{E}-2800$. Sections were frozen at $-20^{\circ} \mathrm{C}$ until use.

\section{Immunohistochemistry}

Sections were thawed at $37^{\circ} \mathrm{C}$ and treated for antigen retrieval with $0.01 \mathrm{M}$ citrate buffer at $\mathrm{pH} 6$ and $70^{\circ} \mathrm{C}$ for 30 $\mathrm{min}$. Those sections containing the thymidine analog were also treated with $0.02 \mathrm{M} \mathrm{HCl}$ at $65^{\circ} \mathrm{C}$ for 30 min for DNA denature. Then, they were incubated in a blocking solution of PBS supplemented with $0.1 \%$ Triton X-100 (Sigma-Aldrich), 5\% normal donkey serum (Accurate Chemicals), and $0.1 \%$ bovine serum albumin (SigmaAldrich) for $1 \mathrm{~h}$ at room temperature. Then, sections were incubated in a mixture of primary antibodies diluted in PBS with $10 \%$ blocking solution at $4^{\circ} \mathrm{C}$ overnight (Table 1 ) followed by incubation with secondary antibodies diluted in PBS for $2 \mathrm{~h}$ at room temperature (Table 1). Nuclei were counterstained by incubating the section with $1 \mu \mathrm{g} / \mathrm{ml}$ DAPI (Invitrogen) and $5 \mu \mathrm{M}$ DRAQ5 (BD Pharmingen). After each step, the sections were carefully washed in PBS. Finally, the sections were mounted with Mowiol 4-88 (Sigma-Aldrich). When immunostaining involved ZsGreen, antibody antigen retrieval was not performed. Please see Table 1 for details about primary and secondary antibodies.

\section{Imaging and quantification}

BrdU images were obtained with an Olympus camera attached to an Olympus BX51 epifluorescence microscope using a $20 \times$ objective lens. For each age group (P7, $n=8$; P25, $n=6)$, BrdU ${ }^{+}$cells were manually quantified from two anatomic locations-dorsal and ventral-of the septal OE in three coronal sections evenly spaced $25 \%, 50 \%$, and $75 \%$ along the anterior-posterior axis for each animal. Cell counts were performed in every image using Fiji software and represented as linear density per millimeter of septal OE. As has been previously reported (Mazzotti et al., 1998; Muñoz-Velasco et al., 2013), we recognized different patterns of BrdU labeling during the S phase of the cell cycle. During early S phase, $\mathrm{BrdU}$ is associated with dispersed chromatin domains far 
from the nuclear envelope, revealing a labeling dispersed throughout the nuclear space. However, during late $S$ phase, BrdU labeling is found in perinuclear heterochromatin regions, revealing a ring-like labeling pattern. Both patterns of BrdU labeling were included in our analyses.

Analyses of Ki67-labeled cells were performed on 20X confocal images (LSM 800, Zeiss), z-stacks were 10-12 $\mu \mathrm{m}$ in depth. Ki67 ${ }^{+}$cells at DPI-B-1, DPI-B-3, DPI-B-5, and DPI-B-7 ( $n=3$ each) were counted using Fiji software from both anatomic locations (dorsal and ventral $\mathrm{OE}$ ) in five coronal sections separated by $750 \mu \mathrm{m}$ along the anterior-posterior axis.

To analyze the radial migration of $\mathrm{BrdU}^{+}$cells in the $\mathrm{OE}$, images were obtained with an Olympus BX51 epifluorescence microscope using a $20 \times$ objective lens. Three coronal sections evenly spaced along the anterior-posterior axis for each animal were analyzed at DPI-B-1, DPIB-3, DPI-B-5, DPI-B-8, DPI-B-10, and DPI-B-12 ( $n=3$ each). To calculate the relative position of $\mathrm{BrdU}^{+}$cells along the OE thickness, we assigned the value 0 to the lamina basal and 1 to the surface of the OE. Then, we calculated the regression line for each image and determined the relative position of every OSN. Finally, to determine accurately the position of each $\mathrm{BrdU}^{+}$cell regardless of the overall height of the $\mathrm{OE}$, we measured the distance between the cell and the basal lamina using Fiji software.

The molecular maturation of OSNs was studied using double immunohistochemistry with BrdU and markers of OSN maturation [Table 1: growth-associated protein 43 (GAP 43), olfactory marker protein (OMP), adenylyl cyclase 3 (AC3)]. Images of BrdU-labeled cells coexpressing one or two different markers were obtained using a $40 \times$ confocal lens (LSM 800, Zeiss) and studied on $1 \mu \mathrm{m}$ sections collected in z-stacks spanning 7-9 $\mu \mathrm{m}$ in depth. For every $z$-stack, each $\mathrm{BrdU}^{+}$nucleus was scanned throughout the 7-9 $\mu \mathrm{m}$ depth to confirm with certainty that the $\mathrm{BrdU}^{+}$nucleus falls perfectly with the OSN expressing each specific marker (GAP 43/AC3/OMP). Three coronal sections evenly spaced along the anterior-posterior axis for each animal were analyzed for colocalization at DPI-B-1, DPI-B-3, DPI-B-5, DPI-B-8, DPI-B-10, and DPI-B-12 using Fiji software. For a more realistic interpretation, all double-immunolabeled cells were normalized to the total number of $\mathrm{BrdU}^{+}$cells counted per region. Data are represented as the percentage of the average among the three animals per time point \pm SEM. For confocal colocalization analyses and quantifications, a total of 305 $\mathrm{BrdU}^{+}$OSNs were counted and analyzed at DPI-B-1, 388 at DPI-B-3, 360 at DPI-B-5, 185 at DPI-B-8, 206 at DPI$\mathrm{B}-10$, and 171 at DPI-B-12.

To study the axonal extension, ZsGreen-labeling was analyzed on 20x and 40x confocal images of 25- $\mu \mathrm{m}$-thick sagittal sections using a Zeiss LSM 800 . For all images, image contrast and brightness were manipulated only for display purposes using Adobe Photoshop CS6.

\section{Experimental design and statistical analysis}

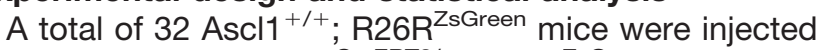
with $\mathrm{BrdU}$, and $30 \mathrm{Ascl} 1^{\mathrm{CreERT}_{2 /+}}$; R26R ${ }^{\text {zsGreen }}$ mice were injected with $4 \mathrm{OH}-\mathrm{Tx}$. For each experiment, animals were injected at different ages and perfused at specific time points for post hoc immunohistochemical analysis, as outlined above in the BrdU and $4 \mathrm{OH}-\mathrm{Tx}$ administration subsection. Multiple sections containing the OE were evaluated per animal, as described in the Imaging and quantification subsection. The resulting data from each analysis were evaluated to apply the appropriate statistical analysis. All the statistical tests were performed using Prism 7 software (GraphPad Software). Every cell count, migration, and maturation analysis were performed blind to the area and time BrdU/4OH-Tx postinjection. Differences among groups were assessed by one-way ANOVA or two-way repeated-measures ANOVA (with Bonferroni's post hoc test), when appropriate. Individual tests for each experiment are specified in detail in the Results, figure legends, and Table 2. All measures across different sections within an animal were averaged to yield one sample replicate for statistical analysis. For all statistics, the number of animals in each group was represented as " $n$." Data are shown as the mean \pm SEM. The significance level was set as $p<0.05$.

\section{Results}

\section{Neurogenesis in the Septal OE at P7 versus P25}

To analyze the dynamics of OSN postnatal neurogenesis, we used BrdU pulse labeling at two different ages: P7 and P25. Following a 7 d survival period, we quantified BrdU labeling in the OE of the dorsal and ventral septum. BrdU labeling was most prominent superior to the basal lamina and was largely limited to the somatic domain of the OSNs (Fig. 1A,B). Scarce labeling at the OE surface, proximal to the lumen of the nasal cavity, reflected ongoing SUS genesis and was not further analyzed (Fig 1a", arrowhead). Labeling deep to the basal lamina in connective tissue and secretory cells was similarly not included in our analyses.

Labeling of newly generated OSN nuclei was robust throughout the OE at both ages (Fig. 1). When comparing the density of $\mathrm{BrdU}^{+}$cells in the septal wall, we found a significant main effect of both factors analyzed, as follows: age $(p<0.001)$ and anatomic location $(p<0.01$; Fig. 1C). The number of $\mathrm{BrdU}^{+}$cells in the ventral septal $\mathrm{OE}$ in P7 mice was 2.2 times higher than that in P25 mice (105.6 \pm 9.2 at $\mathrm{P} 7$ vs $47.03 \pm 7.7$ at $\mathrm{P} 25, p<0.001$; Table 2) and 6 times higher in the dorsal septal OE (103.7 \pm 10.2 at P7 vs $17.1 \pm 5.4$ at P25, $p<0.0001$; Table 2). Likewise, there was a significant age-related distribution of $\mathrm{BrdU}^{+}$cells along the dorsal-ventral axis of the OE. In P7 mice, $\mathrm{BrdU}^{+}$cells were evenly distributed in both dorsal and ventral septal OE (Fig. $1 A, a^{\prime}, a^{\prime \prime}, C$ ). However, at P25, they were highly clustered in the ventral septum (Fig. $\left.1 B, b^{\prime}, b^{\prime \prime}, C\right)$. These results are consistent with an age $\times$ location interaction in the postnatal proliferation of OSNs.

We then turned our attention to the process of OSN genesis in the septal OE at P25 and investigated the cellular mechanisms underlying the scarce number of P25-born $\mathrm{BrdU}^{+}$cells in the dorsal septal OE. First, we assessed whether the number of $\mathrm{BrdU}^{+}$cells underwent significant changes over time depending on their ana- 
Table 2: Summary of statistical analysis used in each experiment

\begin{tabular}{|c|c|c|c|c|c|c|}
\hline Experiment & Test & $p$ Value & Statistical value & Post hoc test & Pairwise comparison & $p$ Value \\
\hline $\begin{array}{l}\text { Figure } 2 \mathrm{C} \\
\text { Num. } \mathrm{BrdU}^{+} \\
\text {(age } \times \text { Anat. location) }\end{array}$ & Two-way RM ANOVA & $\begin{array}{l}\text { Anat. Location }=0.0014 \\
\text { Age }<0.0001 \\
\text { Interaction }=0.003\end{array}$ & $\begin{array}{l}\text { Anat. Location, } F_{(1,12)}=17.19 \\
\text { Age } F_{(1,12)}=36.21 \\
\text { Interaction } F_{(1,12)}=13.28\end{array}$ & $\begin{array}{l}\text { Bonferroni's } \\
\text { correction }\end{array}$ & $\begin{array}{l}\text { Ventral: P7 vs P25 } \\
\text { Dorsal: P7 vs P25 } \\
\text { P7: dorsal vs ventral } \\
\text { P25: dorsal vs ventral }\end{array}$ & $\begin{array}{l}0.0002 \\
<0.0001 \\
\text { n.s. } \\
0.0005\end{array}$ \\
\hline $\begin{array}{l}\text { Figure } 3 E \\
\text { Num. BrdU } \\
\text { (Anat. location } \times \text { time point) }\end{array}$ & Two-way RM ANOVA & $\begin{array}{l}\text { Anat. Location }<0.0001 \\
\text { Time point }=\text { n.s. } \\
\text { Interaction }=\text { n.s. }\end{array}$ & $\begin{array}{l}\text { Anat. Location } F_{(1,8)}=134.7 \\
\text { Time point } F_{(3,8)}=1.947 \\
\text { Interaction } F_{(3,8)}=1.133\end{array}$ & $\begin{array}{l}\text { Bonferroni's } \\
\text { correction }\end{array}$ & $\begin{array}{l}\text { Dorsal vs ventral: } \\
\text { DPI } 1 \\
\text { DPI } 3 \\
\text { DPI } 5 \\
\text { DPI } 7\end{array}$ & $\begin{array}{l}0.0095 \\
0.0006 \\
0.0008 \\
0.0019\end{array}$ \\
\hline $\begin{array}{l}\text { Figure } 3 F \\
\text { Num. Ki } 67^{+} \text {at } \mathrm{P} 25 \\
\text { (Anat. location } \times \text { time point) }\end{array}$ & Two-way RM ANOVA & $\begin{array}{l}\text { Anat. Location }<0.0001 \\
\text { Time point }=0.004 \\
\text { Interaction }=\text { n.s. }\end{array}$ & $\begin{array}{l}\text { Anat. Location } F_{(1,8)}=149.4 \\
\text { Time point } F_{(3,8)}=10.06 \\
\text { Interaction } F_{(3,8)}=2.666\end{array}$ & $\begin{array}{l}\text { Bonferroni's } \\
\text { correction }\end{array}$ & $\begin{array}{l}\text { Dorsal vs ventral: } \\
\text { DPI } 1 \\
\text { DPI } 3 \\
\text { DPI } 5 \\
\text { DPI } 7 \\
\text { Ventral: } \\
\text { DPI } 3 \text { vs DPI } 5\end{array}$ & $\begin{array}{l}0.0014 \\
0.0001 \\
0.0089 \\
0.0018 \\
0.0154\end{array}$ \\
\hline $\begin{array}{l}\text { Figure } 3 G \\
\text { Ventral Num. } \\
\text { BrdU }^{+} \text {vs Ki67 } \\
\text { (marker } \times \text { time point) }\end{array}$ & Two-way RM ANOVA & $\begin{array}{l}\text { Marker = n.s. } \\
\text { Time point = n.s. } \\
\text { Interaction = n.s. }\end{array}$ & $\begin{array}{l}\text { Marker } F_{(1,8)}=0.8985 \\
\text { Time point } F_{(3,8)}=2.71 \\
\text { Interaction } F_{(3,8)}=3.345\end{array}$ & & & \\
\hline $\begin{array}{l}\text { Figure } 4 A \\
\text { Migration P25 } \\
\text { (Anat. location } \times \text { time point) }\end{array}$ & Two-way RM ANOVA & $\begin{array}{l}\text { Anat. Location }=0.0002 \\
\text { Time point }<0.0001 \\
\text { Interaction }=\text { n.s. }\end{array}$ & $\begin{array}{l}\text { Anat. Location } F_{(1,8)}=43.85 \\
\text { Time point } F_{(3,8)}=51.44 \\
\text { Interaction } F_{(3,8)}=3.477\end{array}$ & $\begin{array}{l}\text { Bonferroni's } \\
\text { correction }\end{array}$ & $\begin{array}{l}\text { Dorsal vs ventral: } \\
\text { DPI } 3 \\
\text { DPI } 8 \\
\text { Dorsal: } \\
\text { DPI } 1 \text { vs DPI } 3 \\
\text { Ventral: } \\
\text { DPI } 1 \text { vs DPI } 3 \\
\text { DPI } 5 \text { vs DPI } 8\end{array}$ & $\begin{array}{l}0.0212 \\
0.0026 \\
0.027 \\
<0.0001 \\
0.0025\end{array}$ \\
\hline $\begin{array}{l}\text { Figure } 4 B \\
\text { Migration P25 } \\
\text { (Anat. location } \times \text { time point) }\end{array}$ & Two-way RM ANOVA & $\begin{array}{l}\text { Anat. Location }=0.0001 \\
\text { Time point }=0.0103 \\
\text { Interaction }=0.106\end{array}$ & $\begin{array}{l}\text { Anat. Location } F_{(1,8)}=50.03 \\
\text { Time point } F_{(3,8)}=7.511 \\
\text { Interaction } F_{(3,8)}=2.826\end{array}$ & $\begin{array}{l}\text { Bonferroni's } \\
\text { correction }\end{array}$ & $\begin{array}{l}\text { Dorsal vs ventral: } \\
\text { DPI } 4 \\
\text { DPI } 6 \\
\text { DPI } 8\end{array}$ & $\begin{array}{l}0.0144 \\
0.0254 \\
0.0033\end{array}$ \\
\hline $\begin{array}{l}\text { Figure } 4 C \\
\text { Ventral migration } \\
\text { P25 (time point) }\end{array}$ & One-way ANOVA & $<0.0001$ & $F_{(5,12)}=30.28$ & $\begin{array}{l}\text { Bonferroni's } \\
\text { correction }\end{array}$ & & $\begin{array}{l}\text { n.s. individual } \\
\text { comparisons }\end{array}$ \\
\hline $\begin{array}{l}\text { Figure } 4 E \\
\text { OSNs maturation } \\
\text { (marker } \times \text { time point) }\end{array}$ & Two-way RM ANOVA & $\begin{array}{l}\text { BrdU } / \text { marker }=0.0067 \\
\text { Time point }<0.0001 \\
\text { Interaction }<0.0001\end{array}$ & $\begin{array}{l}\text { Marker } F_{(2,24)}=6.22 \\
\text { Time point } F_{(5,12)}=32.45 \\
\text { Interaction } F_{(10,24)}=13.85\end{array}$ & $\begin{array}{l}\text { Bonferroni's } \\
\text { correction }\end{array}$ & $\begin{array}{l}\text { Marker dynamic: } \\
\text { GAP } 43 \text { : } \\
\text { DPI } 3 \text { vs DPI } 5 \\
\text { DPI } 10 \text { vs DPI } 12 \\
\text { AC } 3 \text { : } \\
\text { DPI } 5 \text { vs DPI } 8 \\
\text { DPI } 8 \text { vs DPI } 10 \\
\text { OMP: } \\
\text { DPI } 8 \text { vs DPI } 10 \\
\text { DPI } 10 \text { vs DPI } 12 \\
\text { Differential marker } \\
\quad \text { expression at } \\
\text { each time point: } \\
\text { DPI } 5 \text { : } \\
\text { GAP } 43 \text { vs AC } 3 \\
\text { GAP } 43 \text { vs OMP } \\
\text { DPI } 8 \text { : } \\
\text { OMP vs AC } 3 \\
\text { OMP vs GAP } 43 \\
\text { DPI } 10 \text { : } \\
\text { AC } 3 \text { vs OMP } \\
\text { DPI } 12 \text { : } \\
\text { GAP } 43 \text { vs AC } 3 \\
\text { GAP } 43 \text { vs OMP }\end{array}$ & $\begin{array}{l}0.0004 \\
<0.0001 \\
0.005 \\
0.0075 \\
\\
0.0055 \\
<0.0001 \\
<0.0001\end{array}$ \\
\hline
\end{tabular}

Anat. location, Anatomic location; num., number; RM, repeated measures; n.s., not significant.

tomic location. We analyzed the density of $\mathrm{BrdU}^{+}$cells in the dorsal and ventral septal OE 1, 3, 5, and $7 \mathrm{~d}$ following BrdU injections. A two-way ANOVA showed a main effect of anatomic location $(p<0.0001)$, but no effect of time postinjection. Post hoc tests showed that the number of $\mathrm{BrdU}^{+}$cells was significantly higher in the ventral area when compared with the dorsal at each time point (Fig. $2 E$ ). Of interest, in both the dorsal and ventral septum BrdU labeling peaked at 3 DPI-B, but did not show a statistically significant effect between the time points that were analyzed when tested with two-way ANOVA (Fig. 2E) (cf. Suzuki and Takeda, 1993; Vedin et al., 2009; Kondo et al., 2010; Savya et al., 2019). Given that the total number of cells is determined by the balance between proliferation rate and cell death, we performed immunostaining for cleaved-caspase-3 (cCasp3), a marker for apoptotic cells, and for Ki67, a cellular marker for proliferation (Fig. $2 A-C$ ). We focused on $\mathrm{Ki}^{+} 7^{+}$cells located 

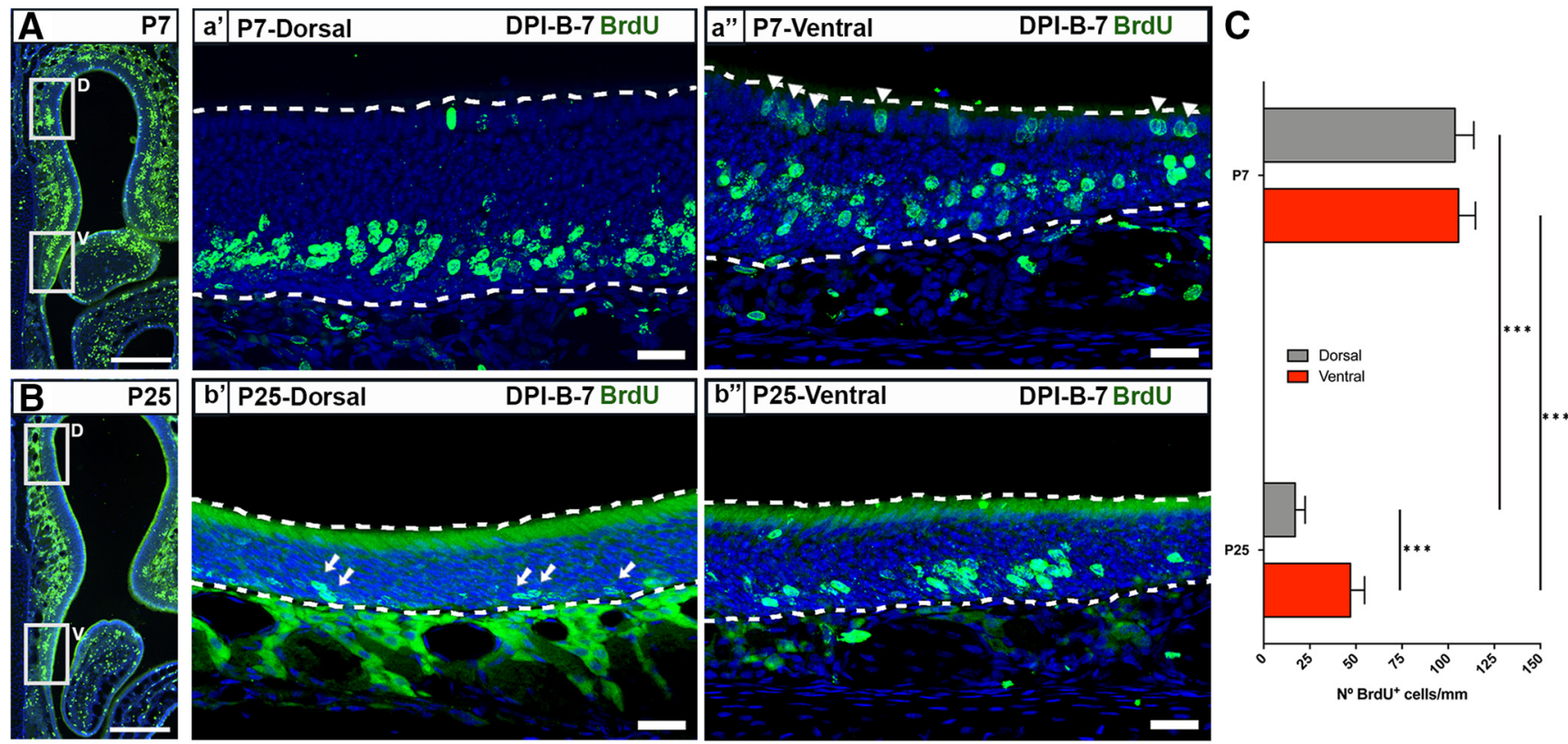

$\mathrm{N}^{\circ} \mathrm{BrdU}^{+}$cells $/ \mathrm{mm}$

Figure 1. Neurogenesis in the septal OE at P7 and P25. A, P7-born OSNs are evenly distributed in the dorsal and ventral zones of the septal OE. $\mathbf{a}^{\prime}, \boldsymbol{a}^{\prime \prime}$, BrdU labeling (green) at DPI-B-7 in the dorsal ( $\left.\boldsymbol{a}^{\prime}\right)$ and ventral $\left(\boldsymbol{a}^{\prime \prime}\right)$ domains of the septum at P7. B, P25-born OSNs are predominant in the ventral zone of the septal OE. $\boldsymbol{b}^{\prime}, \boldsymbol{b}^{\prime \prime}$, Representative image of BrdU labeling (green) at DPI-B-7 in the dorsal $\left(\boldsymbol{b}^{\prime}\right)$ and ventral $\left(\boldsymbol{b}^{\prime \prime}\right)$ domains of the septum at P25. Note the low density of BrdU ${ }^{+}$cells in the dorsal OE at P25 (arrows). $\boldsymbol{C}$, Histograms show the number of $\mathrm{BrdU}^{+}$cells in dorsal and ventral zone of the septal OE at P7 $(n=8)$ and P25 $(n=6)$. The mean \pm SEM values are plotted. $* * * p<0.001$. Dotted white lines delineate OE luminal surface (top) and basal lamina (bottom). DRAQ-5 is in blue. Scale bars: $\boldsymbol{A}, \boldsymbol{B}, 300 \mu \mathrm{m} ; \boldsymbol{a}^{\prime}, \boldsymbol{a}^{\prime \prime}, \boldsymbol{b}^{\prime}, \boldsymbol{b}^{\prime \prime}, 25 \mu \mathrm{m}$.

close to the basal lamina of the $\mathrm{OE}$ (which give rise to future OSNs) and did not study Ki67 ${ }^{+}$cells located in the superficial lamina of the OE that belong to the SUS population. A two-way ANOVA showed a main effect of anatomic location for $\mathrm{Ki}^{+} 7^{+}$cells (Fig. $2 A, B, F ; p<0.0001$ ). However, in contrast to the BrdU data, we also found a significant main effect of time for Ki67 $(p<0.01)$. Post hoc multiple pairwise comparisons established that the number of proliferating neurons significantly decreased from DPI-B-3 to DPI-B-5 in the ventral septal OE. Given that the probability of a type I error is higher when repeated measures of two-way ANOVAs are applied, we next compared the number of $\mathrm{BrdU}^{+}$and $\mathrm{Ki}^{+} 7^{+}$cells at different time points. Statistical analyses did not show a significant effect of time on the number of $\mathrm{BrdU}^{+}$and $\mathrm{Ki} 67^{+}$cells in the ventral septal OE (Fig. 2G; $p=$ n.s.), supporting the idea of a possible type I error (Table 2, for statistical analysis applied and $p$ values). These results are consistent with prior work demonstrating that cells expressing Ascl1, a transcription factor in nascent OSNs, are few in number in the dorsomedial part of the OE in 8-week-old mice, but not in 1-week-old mice (Vedin et al., 2009).

The number of $\mathrm{cCasp}^{+}$cells in the septal OE was too small to permit statistical analysis. We observed only one to two cCasp $3^{+}$cells along the whole length of the bilateral septal OE in 2 of 12 animals. However, when we analyzed five sections per animal from four different time points ( $n=3$, for each time point), we observed that the presence of apoptotic cells in the turbinates was higher when compared with the septum (Figs. $2 C, 3$ ). These results are consistent with the notion that programmed cell death, OSN apoptosis, can vary throughout the OE.

\section{Differentiation and maturation of P25-born OSNs}

Newborn cells initially located close to the basal lamina undergo morphologic and molecular transitions as they differentiate into mOSNs, including radial migration into the OE. To investigate the differentiation and maturation of OSNs, we first analyzed their radial migration within the $\mathrm{OE}$. Because the thickness of the OE is not equal in the dorsal and ventral regions of the septum in P25 mice, we analyzed the relative positions of OSNs along the basalapical axis of the dorsal and ventral septal OE. We assigned the value 0 to the basal lamina and the value 1 to the surface of the OE, adjacent to the lumen of the nasal cavity. We found that P25-born OSNs are located in the lower $10 \%$ of the OE at DPI-B-1 in both dorsal and ventral regions of the septum (Fig. 4A). Subsequently, after DPI$\mathrm{B}-1$, neurons migrate at different rates in an anatomic location-dependent manner. P25-born OSNs are located in the lower $15 \%$ of the $\mathrm{OE}$ in the dorsal region of the $\mathrm{OE}$ between DPI-B-3 and DPI-B-5, while they reached $21 \%$ of the $\mathrm{OE}$ in the ventral region, suggesting a faster migration. Finally, by DPI-B-8 they reached the $20 \%$ of the OE in the dorsal region and the $30 \%$ in the ventral area of the septal OE. A two-way ANOVA comparing the relative positions of cells at different time points in the dorsal and ventral septal $O E$, showed a significant main effect of both of the factors time $(p<0.0001)$ and anatomic location $(p$ $<0.001)$. These data suggest that cells migrate radially following basal cell division in both the dorsal and ventral 


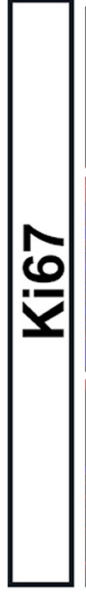

\section{A}
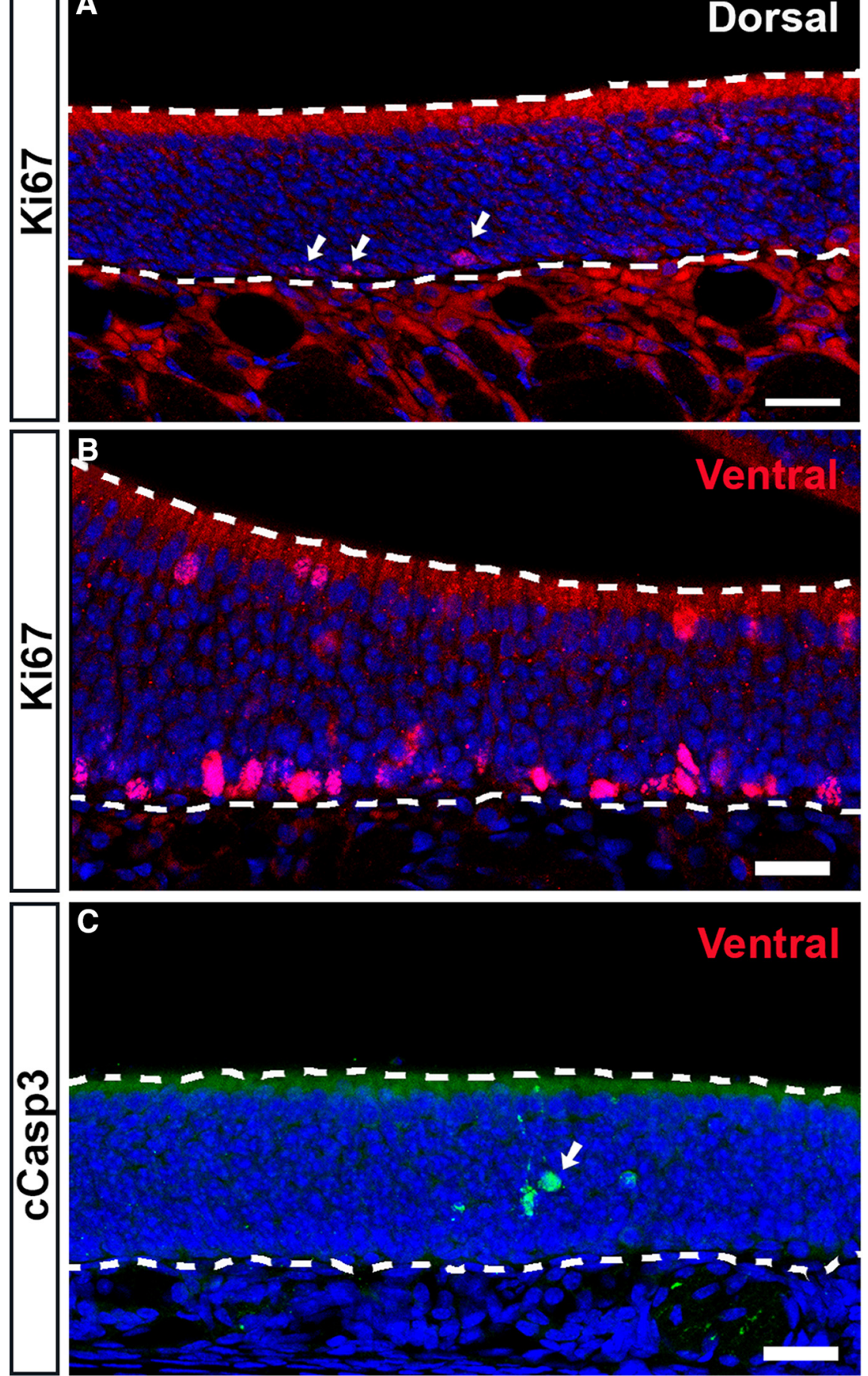

Figure 2. Cell proliferation in the septal wall of the OE in P25 mice. $\boldsymbol{A}, \boldsymbol{B}$, Maximum intensity projections of confocal $z$-stacks showing Ki67-expressing cells (red) in the dorsal $(\boldsymbol{A})$ and ventral $(\boldsymbol{B})$ domains of the septum. Note the low density of Ki67 $7^{+}$cells in the dorsal zone (arrows). Ki67-labeled cells at the luminal surface of the ventral septum are sustentacular cells. $\boldsymbol{C}$, Confocal image showing cCasp3-expressing cells in the ventral septal OE (green). Note the low number of apoptotic cells (arrow). $\boldsymbol{D}$, Illustration of the OE from a coronal perspective. Black and red rectangles represent dorsal and ventral zones of the septal OE, respectively. $\boldsymbol{E}$, $\boldsymbol{F}$, Histograms show the number of $\mathrm{BrdU}^{+}$cells per millimeter $(\boldsymbol{E})$ and $\mathrm{Ki}^{+} 7^{+}$cells per millimeter $(\boldsymbol{F})$ in the dorsal and ventral zones of the septal OE at different following time points after BrdU injections: DPI-B-1, DPI-B-3, DPI-B-5, and DPI-B-7. The mean \pm SEM values are plotted $(n=3)$. G, Histogram representing the number of $\mathrm{BrdU}^{+}$and $\mathrm{Ki}^{+} 7^{+}$cells in the ventral septal OE. The mean $\pm \mathrm{SEM}$ values are plotted. $* * p<0.01, * * * p<0.001$. Dashed white lines delineate the surface of the OE (top) and basal lamina (bottom). DRAQ-5 is in blue. Scale bars, $25 \mu \mathrm{m}$. 


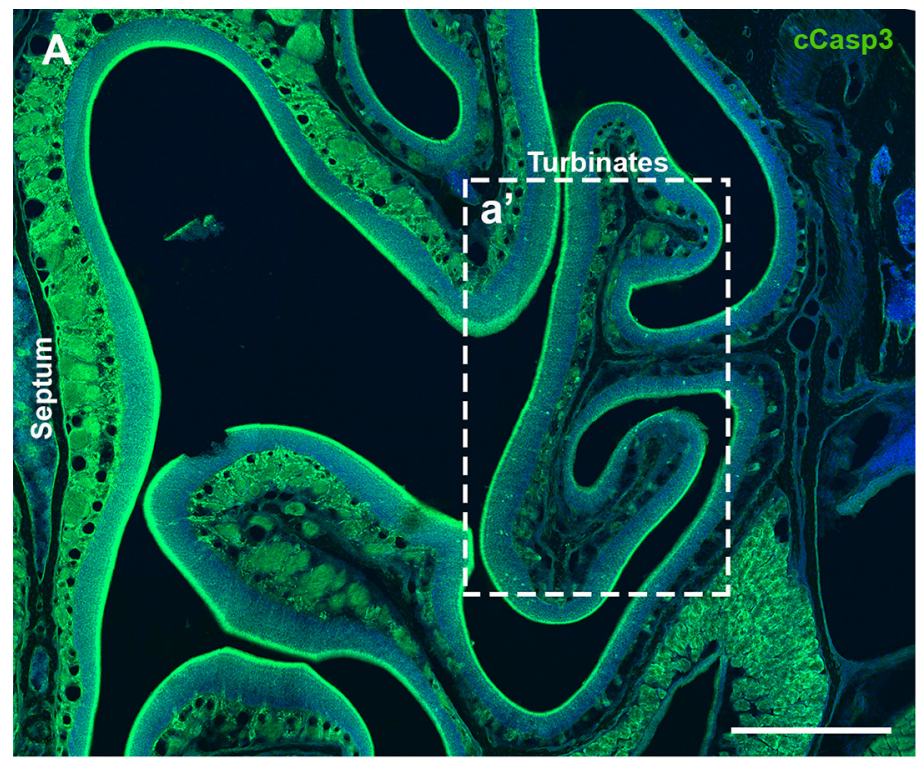

septum
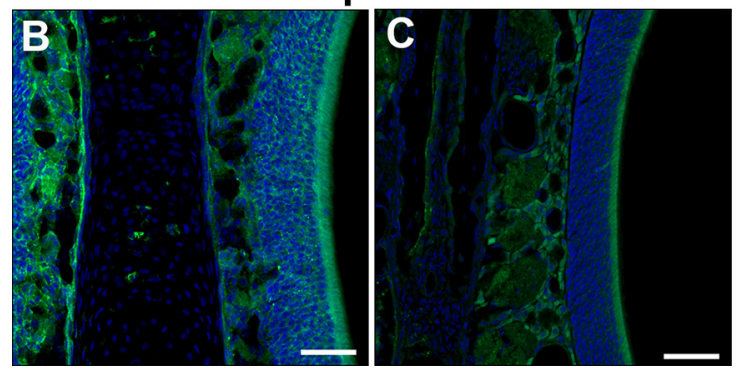

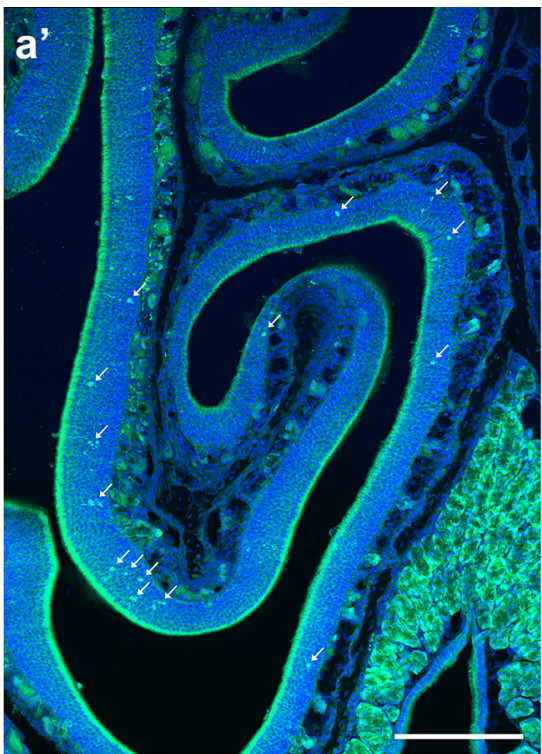

\section{turbinates}
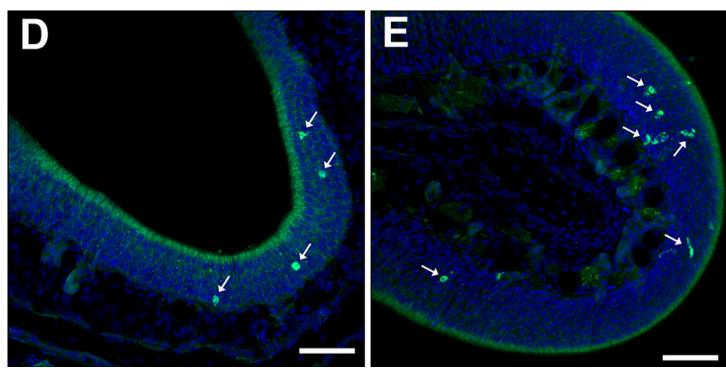

Figure 3. Cell death in the OE in P25 mice. A, Semipanoramic view of the OE including the septum and turbinates. $\boldsymbol{a}^{\prime}$, Caspase $3^{+}$ cells (green) are mainly spread across the turbinates (arrows). Almost no caspase $3^{+}$cells were observed along the septal wall. $\boldsymbol{B}$, $\boldsymbol{C}$, High magnification of the septal wall showing the absence of caspase $3^{+}$cells. $\boldsymbol{D}, \boldsymbol{E}$, High magnification of different turbinates showing the presence of several caspase $3^{+}$cells (arrows). Scale bars: $\boldsymbol{A}, 400 \mu \mathrm{m} ; \boldsymbol{a}^{\prime}, 200 \mu \mathrm{m} ; \boldsymbol{B}-\boldsymbol{E}, 50 \mu \mathrm{m}$.

domains of the septum, but they differ in the rate of migration depending on the anatomic location. Post hoc multiple pairwise comparisons displayed significantly different relative locations of cells at different time points when dorsal and ventral areas of the septal OE were compared (Fig. 4A; Table 2, for statistical analysis applied and $p$ values). In like manner, the relative locations of cells is significantly different between DPI-B-1 and DPI-B-3 in the dorsal and ventral OE, and between DPI-B-5 and DPI-B-8 in the ventral part of the septal wall (Table 2, for statistical analysis applied and $p$ values).

Because the ventral $\mathrm{OE}$ is thinner than the dorsal $\mathrm{OE}$, the use of the ratio may not give a fully accurate assessment of migration rate. To test further that the migration rate differs in the dorsal versus ventral $\mathrm{OE}$, we measured the distance (in micrometers) between the cell body and the basal lamina at different time points following the administration of BrdU. A two-way ANOVA comparing the distance traveled by $\mathrm{BrdU}^{+}$cells in both anatomic locations at different time points showed a main effect of both factors time $(p<0.05)$ and anatomic location $(p<0.001)$. Post hoc multiple pairwise comparisons displayed significant difference in the distance traveled by cells at DPIB-4, DPI-B-6, and DPI-B-8 when dorsal and ventral areas of the septal OE were compared (Fig. $4 B$; Table 2, for statistical analysis applied and $p$ values).

Given the low number of P25-born OSNs in the dorsal septal OE, we focused on OSNs produced in the ventral region of the septum. First, we expanded the analysis of radial migration by adding two more time points to our analyses. We found that P25-born neurons reached the $40 \%$ of the OE by DPI-B-10 and that they resided in the middle of the OE by DPI-B-12. One-way ANOVA showed a significant difference in the relative positions of P25born OSNs over time in the ventral region of the OE $p<$ 0.0001; Fig. 4C; Table 2, for statistical analysis applied and $p$ values).

Our next aim was to determine when newborn OSNs differentiate and become mOSNs. To accomplish that goal, we used BrdU pulse-chase experiments, and waited $1,3,5,8,10$, and $12 \mathrm{~d}$ after BrdU injections to perfuse the animals, collect tissue, and carry out double-labeled immunohistochemistry to uncover the relative timing of maturation-related protein expression in P25-born cells. We used immunohistochemistry to determine the expression of the following: GAP 43 (Fig. 4D1,D4,D5), a protein expressed specifically in iOSNs; AC3 (Fig. 4D2,D6,D7), an enzyme that catalyzes the conversion of ATP to cAMP 
A

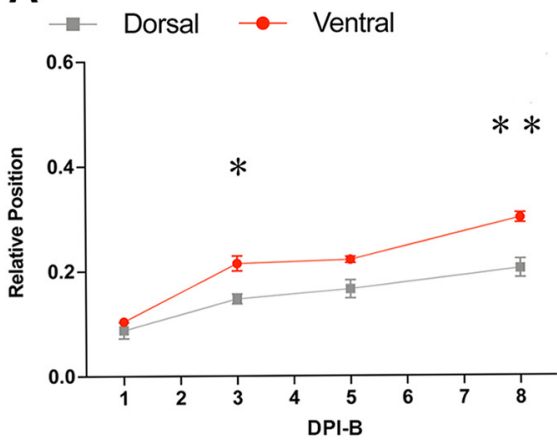

B

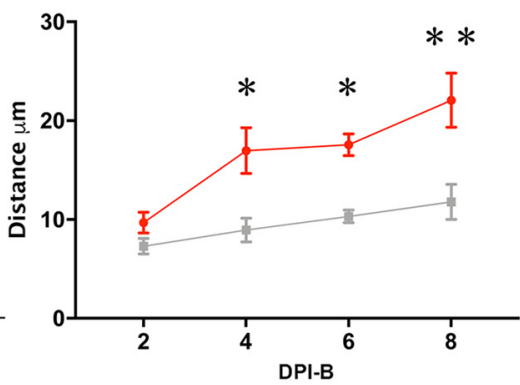

C

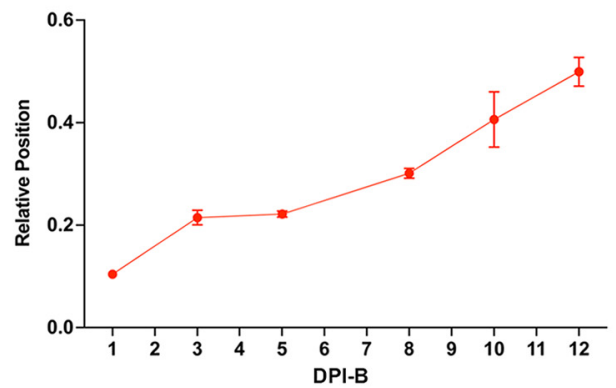

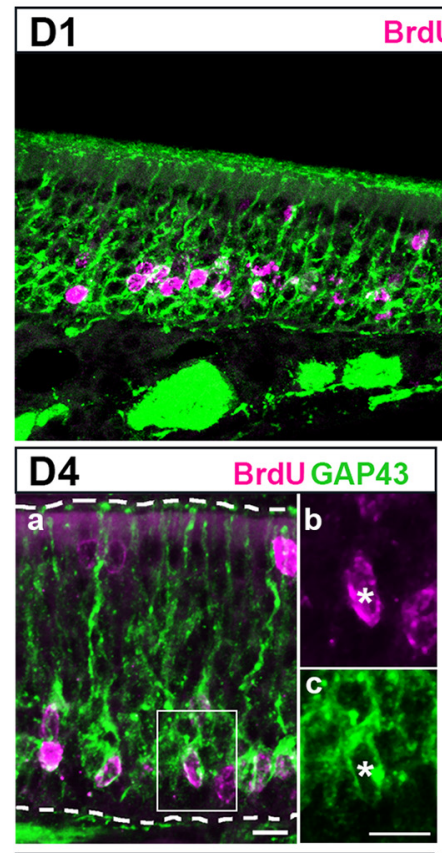

\section{D8}

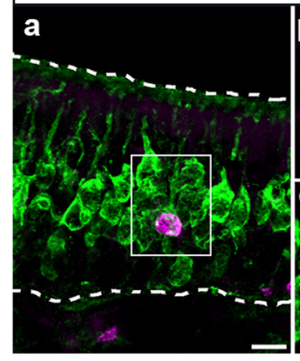

BrdU OMP

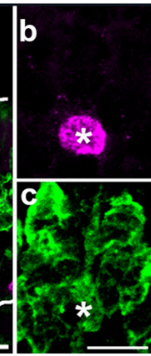

BrdU GAP43

\section{D2}

DPI-B-5
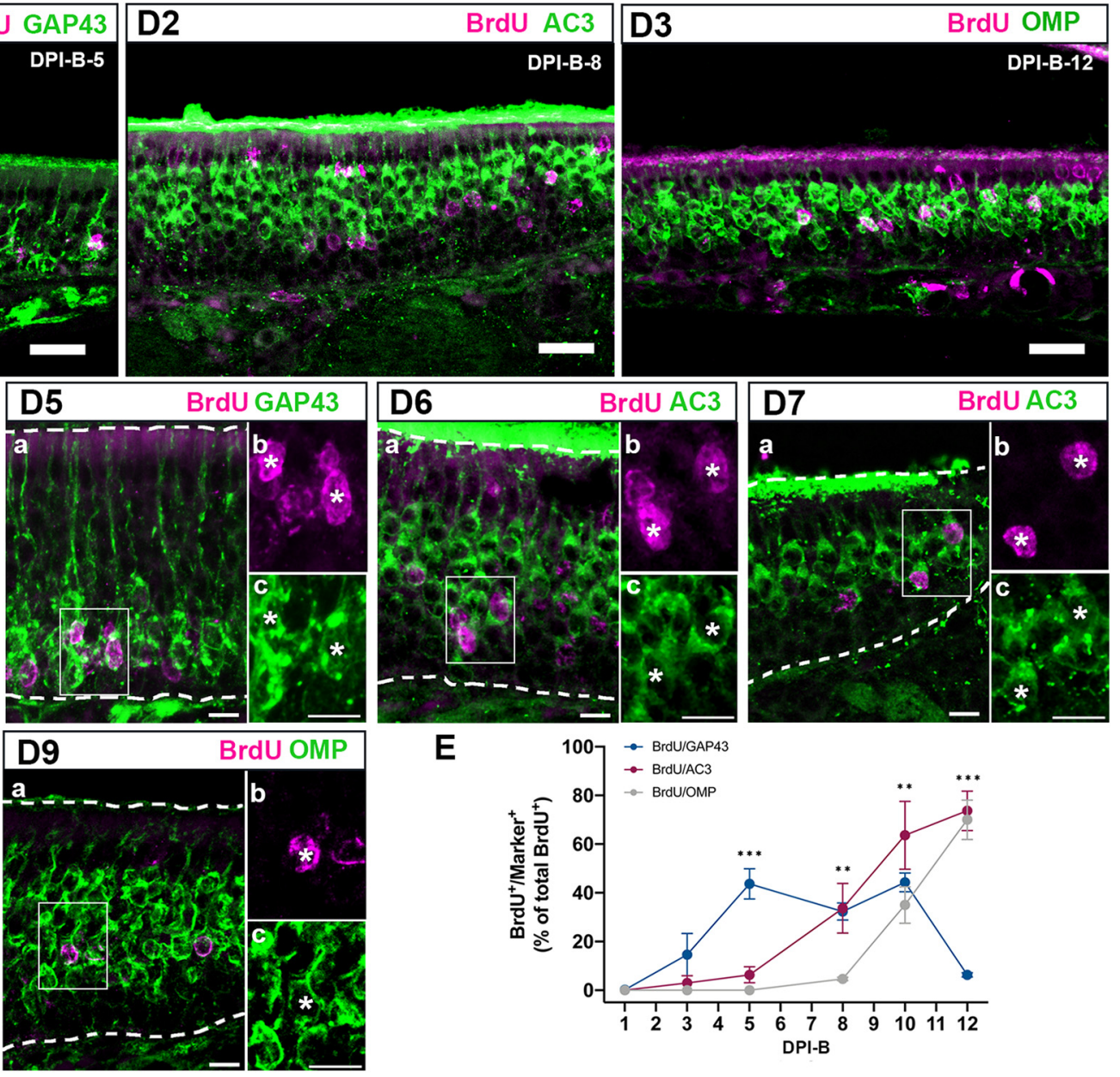

E

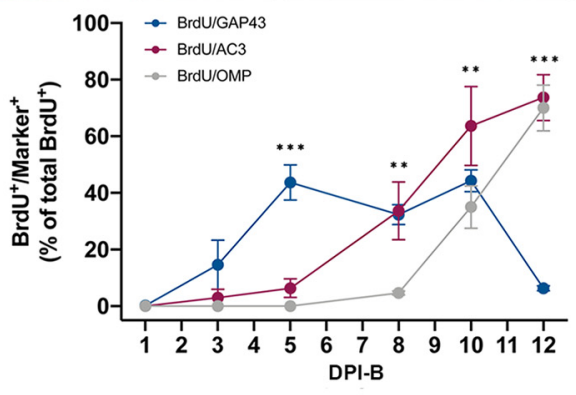

Figure 4. Migration and maturation of P25-born OSNs in the septal OE. A, Newborn OSNs migrate radially in the OE. Graph showing relative radial position of $\mathrm{BrdU}^{+}$cells in the dorsal (gray) and ventral (red) septal OE at different time points after BrdU injections. $\boldsymbol{B}$, Graph showing the distance between $\mathrm{BrdU}^{+}$cells and the basal lamina; distance is represented in micrometers. $\boldsymbol{C}$, Relative position of P25-born OSNs in the ventral zone of the septum at six different time points during a $12 \mathrm{~d}$ timecourse after BrdU administration. The mean \pm SEM values are plotted $(n=3)$. $* p<0.05, * * p<0.01$. $\boldsymbol{D}$, Coimmunolabeling for BrdU (magenta) and markers of maturation (green): GAP 43, AC3, and OMP at different time points after BrdU administration. D1-D3, Confocal images at low magnification representing flattened stacks of 10-12 1- $\mu \mathrm{m}$-thick optical sections. D4-D9, High-magnification confocal images representing flattened stacks of seven to nine 1- $\mu$ m-thick optical sections. GAP 43 and BrdU costaining at DPI-B-5 (D4, D5). AC3 and BrdU costaining at DPI-B-8 (D6, D7). OMP and BrdU costaining at DPI-B-12 (D8, D9). In D4a-c to D9a-c, square cells (a) are magnified in $\boldsymbol{b}$ showing BrdU labeling, and in $\boldsymbol{c}$ showing the corresponding markers GAP 43, AC3, and OMP. In both $\boldsymbol{b}$ and $\boldsymbol{c}$, colabeled cells are marked with an asterisk. $\boldsymbol{E}$, Line graph showing the percentage of colabeled (marker/BrdU) cells of the total number of $\mathrm{BrdU}^{+}$cells counted. Transition from immature to mature OSN occurs at $10 \mathrm{~d}$ after basal cell division. OSNs first express AC3 at $5 \mathrm{~d}$ post-basal cell division. OMP expression is not evident until $8 \mathrm{~d}$ post-basal cell division. The mean \pm SEM values are plotted $(n=3)$. $* * p<0.01, * * * p<0.001$. Dashed white lines delineate the surface of the OE (top) and basal lamina (bottom). DRAQ-5 is in blue. Scale bars: D1-D3, $25 \mu \mathrm{m} ; \boldsymbol{D 4} \mathbf{D} \mathbf{9}, 10 \mu \mathrm{m}$. 
and plays a key role in axonal projection, postnatal maturation, and OR stabilization (Trinh and Storm, 2003; Chesler et al., 2007; Col et al., 2007; Zou et al., 2007; Lyons et al., 2013; Zhang et al., 2017); and olfactory marker protein (OMP; Fig. 4D3,D8,D9), a maturation marker in OSNs whose expression correlates with the onset of synaptogenesis (Farbman and Margolis, 1980; Monti Graziadei et al., 1980). For a more realistic comparison between $\mathrm{BrdU}^{+}$cells expressing each marker at different time points, the results are presented as a percentage (Fig. 4E). All double-labeled cells were normalized to the total number of $\mathrm{BrdU}^{+}$cells counted per linear unit (220 $\mu \mathrm{m}$ of length). Our results illustrate that $\mathrm{BrdU}^{+}$ cells expressing GAP 43 were rare until DPI-B-3, when $14.67 \%$ of the total number of $\mathrm{BrdU}^{+}$cells were GAP $43^{+}$. $\mathrm{BrdU}^{+} / \mathrm{GAP} 43^{+}$cells peaked at DPI-B-5, representing an average of $44 \%$ of the total $\mathrm{BrdU}^{+}$cells and remained high until DPI-B-10, before they decreased abruptly at DPI-B-12 $\left(6.33 \%\right.$ of the total number of $\mathrm{BrdU}^{+}$cells). When compared with GAP 43, OMP expression appeared significantly later. $\mathrm{BrdU}^{+} / \mathrm{OMP}^{+}$cells were observed at DPI-B-8 for the first time and constituted only the $4.67 \%$ of total $\mathrm{BrdU}^{+}$at that time. However, the percentage of $\mathrm{BrdU}^{+} / \mathrm{OMP}^{+}$increased significantly after DPI-B-8, constituting $35 \%$ of the total number of $\mathrm{BrdU}^{+}$cells at DPI$\mathrm{B}-10$, and $70 \%$ at DPI-B-12, reflecting the timescale when the expression of GAP 43 declines. In like manner, we analyzed the AC3 timeline of expression and demonstrated that it preceded OMP expression. An average of $6.33 \%$ of the total number of $\mathrm{BrdU}^{+}$cells expressed $\mathrm{AC} 3$ at DPI-B-5, and its expression increased steadily onward. At DPI-B-8, 33.67\% of the total number of $\mathrm{BrdU}^{+}$cells expressed AC3, and this percentage increased to $63.67 \%$ and $73.67 \%$ at DPI-B-10 and DPI-B-12, respectively. Statistical analyses showed a significant main effect of time on each marker expression $(p<0.0001)$. Likewise, analyses showed a main effect of marker $(p<0.01)$, which means that the expression of the three markers is significantly different at each day following basal cell division. Finally, there is a significant interaction effect between the factors markers and time $(p<0.0001)$. Post hoc multiple pairwise comparisons showed that, chronologically, the percentage of $\mathrm{BrdU}^{+} / \mathrm{GAP} 43^{+}$cells increased abruptly from DPI-B-3 to DPI-B-5 and then decreased dramatically from DPI-B-10 to DPI-B-12. In contrast, $\mathrm{BrdU}^{+} / \mathrm{OMP}^{+}$ cells are rare or nonexistent until DPI-B-8, but increased significantly fast during the following days (DPI-B-10 and DPI-B-12). Right before the expression of OMP, $\mathrm{BrdU}^{+}$ cells were also $\mathrm{AC3}^{+}$. The percentage of $\mathrm{BrdU}^{+} / \mathrm{AC}^{+}$ cells underwent a steady increase from DPI-B-5 onward. When post hoc multiple pairwise comparisons were applied, the number of $\mathrm{BrdU}^{+} / \mathrm{GAP} 43^{+}$cells was shown to be significantly different from the average of $\mathrm{BrdU}^{+} / \mathrm{AC}^{+}$ and $\mathrm{BrdU}^{+} / \mathrm{OMP}^{+}$cells at DPI-B-5 and DPI-B-12. Similarly, the number of $\mathrm{BrdU}^{+} / \mathrm{OMP}^{+}$cells was significantly different from the number of $\mathrm{BrdU}^{+} / \mathrm{GAP} 43^{+}$cells at DPI-B-8 and the number of $\mathrm{BrdU}^{+} / \mathrm{AC}^{+}$cells at DPI-B-8 and DPI-B-10 (Table 2, for appropriate test and $p$ values). The timecourse and molecular characteristics of P25born OSN maturation are summarized in Figure 5.
Our results showed that $\mathrm{P} 25$-born OSNs start expressing AC3 immediately before they express OMP, which is interpreted as indicative of an mOSN, analogous to perinatal stages (Rodriguez-Gil et al., 2015). Functionally, AC3 is required for odor perception and successful OSN axonal projection, and is implicated in OSN maturation (Zhang et al., 2017). In light of this, and knowing that 10 and $12 \mathrm{~d}$ following basal cell division a significant percentage of P25-born OSNs express AC3 and OMP (Figs. $4 E, 5)$, we asked whether their expression follows a sequential fashion or whether, on the contrary, there are mOSNs $\left(\mathrm{OMP}^{+}\right.$cells) that do not express AC3. To address this question, we conducted triple immunostaining for BrdU, AC3, and OMP (Fig. 6A,C-E). The results showed that at DPI-B-10 an average of $23.08 \%$ of total $\mathrm{BrdU}^{+}$cells express $\mathrm{AC} 3$, only $1.1 \%$ of total $\mathrm{BrdU}^{+}$were $\mathrm{BrdU}^{+} / \mathrm{OMP}^{+}$, and $32.97 \%$ of total $\mathrm{BrdU}^{+}$cells express both markers AC3 and OMP (Fig. 6B). At DPI-B-12, $13.89 \%$ of total $\mathrm{BrdU}^{+}$cells were also $\mathrm{AC}^{+}$, and $11.11 \%$ of $\mathrm{BrdU}^{+}$OSNs expressed only OMP, but not AC3 (Fig. $6 B, C$, dotted square, $E$, arrow). The percentage of $B$ dUU $^{+}$ cells expressing both markers $A C 3$ and OMP increased to $63.89 \%$ at DPI-B-12 (Fig. 6B,C, dotted circle, 6D, dotted circle). These data demonstrate that most of the $\mathrm{BrdU}^{+} /$ $\mathrm{OMP}^{+} \mathrm{OSN}$ s previously expressed AC3 at DPI-B-10 and DPI-B-12, corroborating the hypothesis of sequential expression. We observed only a small percentage of $\mathrm{BrdU}^{+}$ cells expressing OMP, but not AC3, at DPI-B-12 (Fig. $6 B, C$, dotted square, $6 E$, arrow).

\section{Axon extension from the $O E$ to the $O B$}

Once we analyzed the neurogenesis, radial migration, differentiation, and molecular maturation processes of the OSNs in the septal wall of the OE in young adults, we analyzed the maturation of these neurons by defining the time course and spatiotemporal features of their axon extension from the OE to the OB. To achieve this aim, we used an in vivo genetic fate-mapping strategy that allows us to label, in a very narrow temporal window, globose basal cells that function as transit-amplifying neuronally committed progenitor cells and express Ascl 1 (Schwob et al., 2017). We used transgenic mice that express an inducible Cre enzyme fused to estrogen receptor (i.e., CreERT2) under Ascl 1 promoter, Ascl1 ${ }^{\mathrm{CreERT} /+}$ (Kim et al., 2011). Then we crossed them with $\mathrm{R} 26 \mathrm{R}^{\mathrm{ZsG} \text { Green/ZsGreen }}$ reporter mice to obtain the double transgenic mice used for our experiment, Ascl1 ${ }^{\text {CreERT2/+}}$; R26R ZsGreen (Fig. 7A). The fused protein CreERT2 stays enzymatically inactive in the cytoplasm in the absence of $4 \mathrm{OH}-\mathrm{Tx}$, but becomes transiently active after $4 \mathrm{OH}-\mathrm{Tx}$ administration. In the cytoplasm, $4 \mathrm{OH}-\mathrm{Tx}$ binds CreERT2 with high affinity and translocates the fusion protein into the nucleus, where Cre enzyme recombines, allowing ZsGreen expression. To test the accuracy of the model, we ran several control experiments (see Materials and Methods).

In the same manner as the BrdU pulse chase, this model allowed us to use a different technique to analyze and confirm that P25-born somata migrated apically toward the lumen as they mature (Fig. $8 A-D$ ). However, 


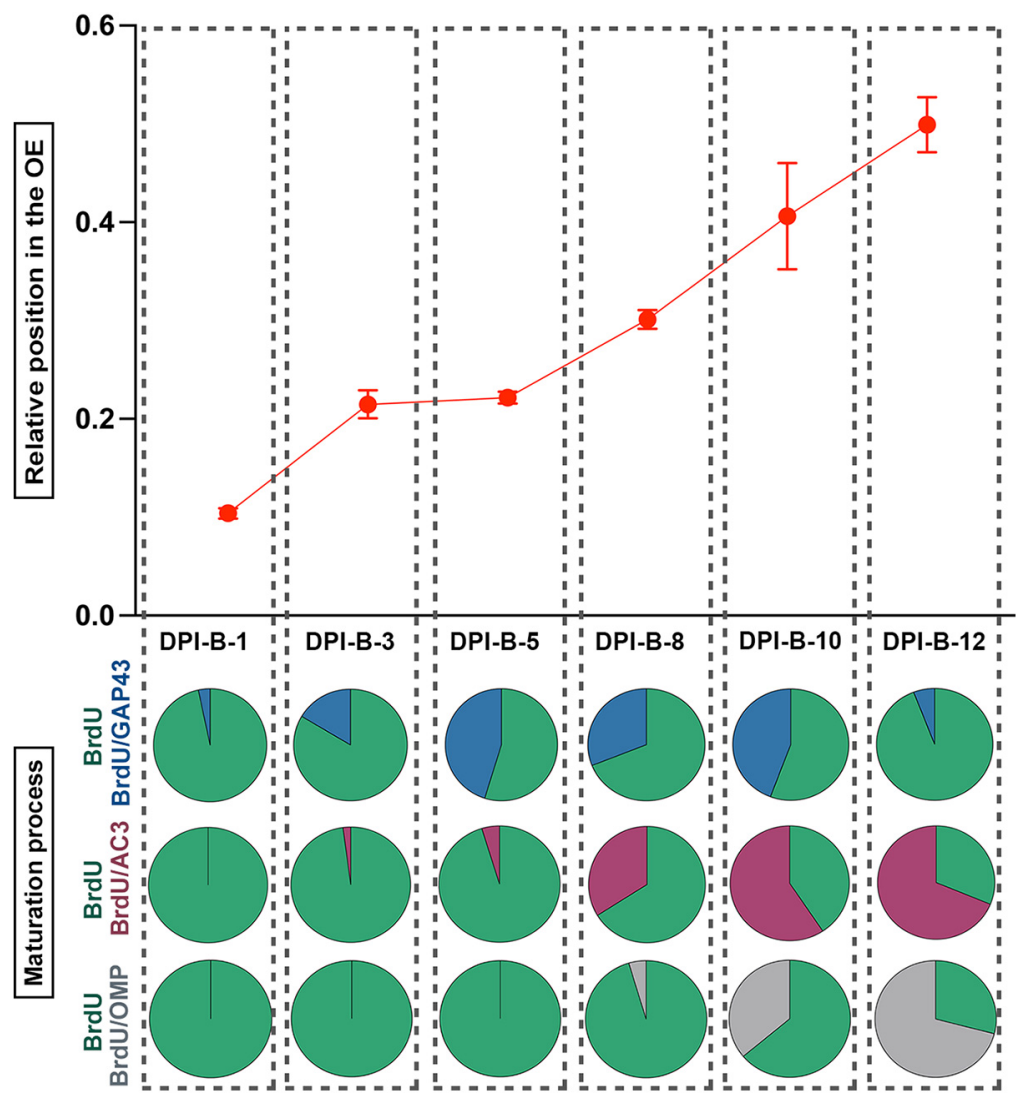

Figure 5. Summary correlating migration and maturation of P25-born OSNs in the ventral zone of the septal OE. Top diagram shows the relative radial position of $\mathrm{BrdU}^{+}$cells throughout the $\mathrm{OE}$ during a $12 \mathrm{~d}$ timecourse following BrdU administration. Pie charts located on the bottom half of the diagram show the percentage of the following costaining cells: $\mathrm{BrdU}^{+} / \mathrm{GAP}^{4} 3^{+}(\mathrm{blue}), \mathrm{BrdU}^{+} / \mathrm{AC}^{+}$ (red), and $\mathrm{BrdU}^{+} / \mathrm{OMP}^{+}$(gray) of the total number of $\mathrm{BrdU}^{+}$cells counted. BrdU ${ }^{+}$cells not expressing any other marker are represented in green. Dotted vertical columns represent each time point of analysis after BrdU administration: DPI-B-1, DPI-B-3, DPI-B-5, DPI-B-8, DPI-B-10 and DPI-B-12.

contrary to BrdU strategy, the inducible Cre-LoxP system allowed us to label OSNs entirely, and we could detect ZsGreen labeling strongly expressed throughout the cytoplasm and processes of OSNs. Thus, we analyzed the spatiotemporal morphologic features of $\mathrm{ZsGreen}^{+}$OSNs at 10 different time points following $4 \mathrm{OH}-\mathrm{Tx}$ injection (DPI-Tx-1, -2, -3, -4, -5, -6, -7, -8, -10, and -12).

At DPI-Tx-1, ZsGreen labeling revealed only cell bodies that were proximal to the basal lamina of the OE (Fig. 8A). Although scarce labeled processes were observed at this point, no evidence of polarity in the OSN was detected. In other words, both the apical dendrite and axon appear simultaneously following basal cell division (Fig. 9A,B). Noticeably, processes from OSNs were clearly distinguished by DPI-Tx-2. ZsGreen ${ }^{+}$OSNs extended apical dendrites radially toward the surface of the OE, some of which reached the lumen of the nasal cavity and exhibited a dendritic knob (Fig. 8B, arrows). Those that did not reach the surface showed dilated elliptical tips that resembled dendritic growth cones (Fig. 8B, arrowhead). Within the lamina propria, the first ZsGreen ${ }^{+}$axons were observed at DPI-Tx-2 (Fig. 8B, asterisk). At DPI-Tx-3, the vast majority of ZsGreen ${ }^{+}$apical dendrites reached the lumen of the nasal cavity and showed a dendritic knob (Fig. 8C, arrow). Occasionally, we could distinguish some cilia extending from the knob (Fig. 8D, arrow). By DPI$\mathrm{Tx}-3$, numerous $\mathrm{ZsGreen}^{+}$axons grouped and formed nerve fascicles that traveled toward the $\mathrm{OB}$ (Fig. 8C, asterisk, E). By DPI-Tx-4, the fascicles of ZsGreen ${ }^{+}$axons extending from the $\mathrm{OE}$ to the $\mathrm{OB}$ (Fig. 8F, arrows) began to cross the cribriform plate (Fig. 8F). By DPI-Tx-5, after crossing the cribriform plate, ZsGreen ${ }^{+}$axons joined the olfactory nerve layer (ONL) on the surface of the OB (Fig. $8 G$, arrow), where they were mainly confined to the outer ONL (oONL; Fig. 8G,H). At DPI-Tx-6, labeled axons reached the inner ONL (iONL; Fig. 8/) and then expanded their innervation of this layer by DPI-Tx-7 and DPI-Tx-8 (Fig. $10 A, B$ ) by surrounding olfactory glomeruli of the ventrolateral OB (Fig. 10F). Although occasionally a few ZsGreen $^{+}$axons were observed within the glomerular neuropil at DPI-Tx-8, they were clearly ramifying within the glomerular neuropil by DPI-Tx-10 (Fig. 10C). Moreover, this strategy also allowed us to identify several axon growth cones, revealing that those young axons are indeed pathfinding (Fig. 10E). We did find a noticeable decrease in ZsGreen labeling at DPI-Tx-10 and DPI-Tx-12 (Fig. 10C,D) compared with prior time points. The most parsimonious explanation for this is the occurrence of changes in the stability of the fluorescent protein ZsGreen over time. 

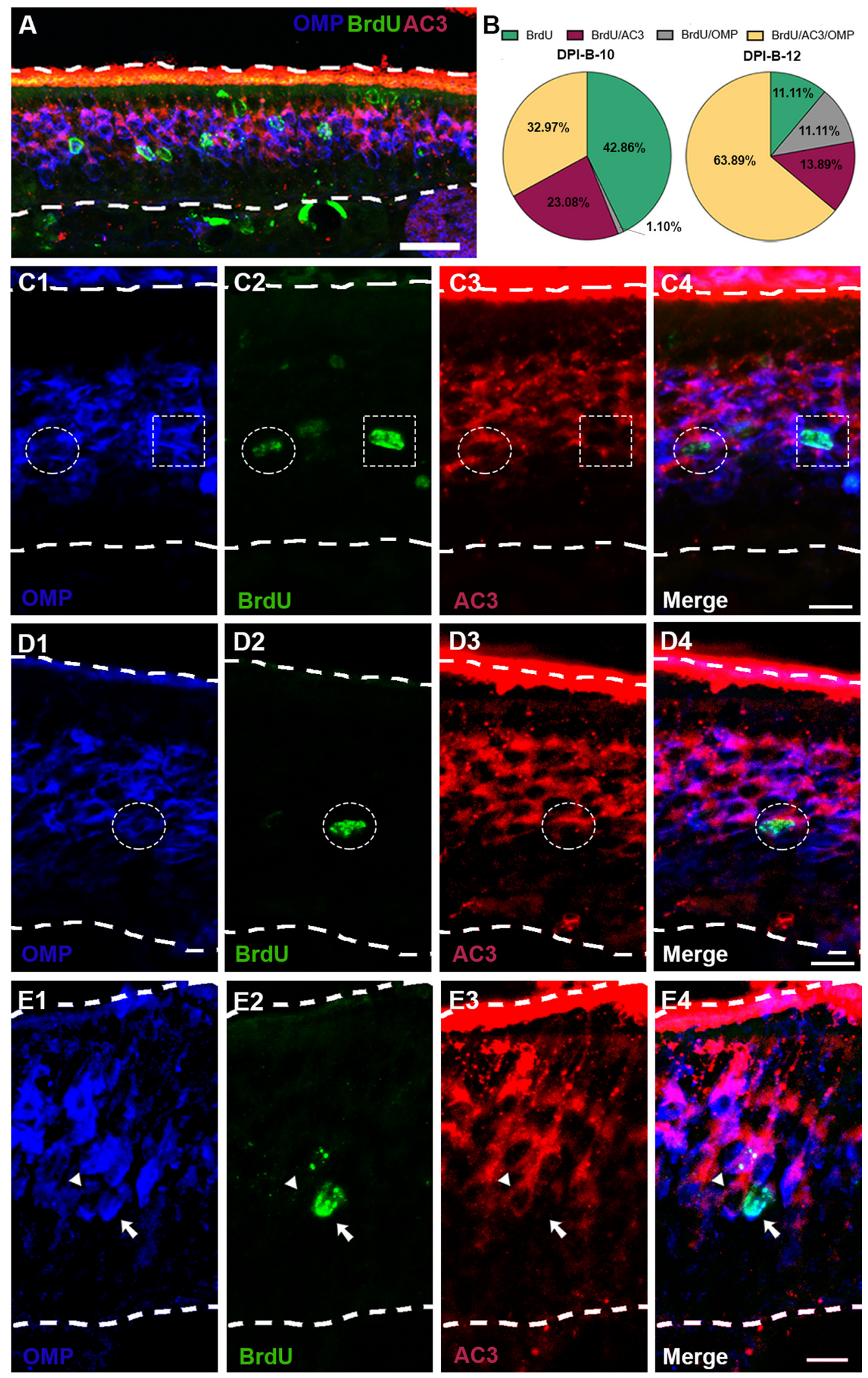

Figure 6. BrdU/AC3/OMP triple immunostaining at 10 and $12 \mathrm{~d}$ following BrdU administration. $\boldsymbol{A}$, Confocal image at low magnification representing flattened stacks of seven to nine 1- $\mu$ m-thick optical sections. BrdU ${ }^{+}$(green) OSNs coexpressing AC3 (red) and OMP 


\section{continued}

(blue) at day 12 after BrdU injections (arrows). B, Pie charts quantifying BrdU ${ }^{+}$cells expressing AC3 (maroon) or OMP (gray), coexpressing AC3 and OMP (yellow), or not expressing either AC3 and/or OMP (green) at DPI-B-10 and DPI-B-12. C, D, Higher-magnification confocal images showing examples of BrdU ${ }^{+}$cells (green) coexpressing AC3 (red) and/or OMP (blue). C1-C4, Dotted circle denotes a BrdU ${ }^{+}$cell $(\mathbf{C} 2$, green) coexpressing OMP $(\mathbf{C 1}$, blue) and AC3 (C3, red), while a dotted square highlights a $\mathrm{BrdU}^{+}$cell $(\mathbf{C 2}$, green) expressing OMP (C1, blue), but not AC3 (C3, red); $\mathbf{C} 4$ shows a merged image. D1-D4, A dotted circle shows a $\mathrm{BrdU}^{+}$cell $(\boldsymbol{D} 2$, green) coexpressing OMP (D1, blue) and AC3 (D3, red); $\boldsymbol{D} 4$ shows a merged image. E1-E4, Arrow pointing to a $\mathrm{BrdU}^{+}$cell (E2, green) expressing OMP (E1, blue), but not AC3 (E3). Next to the BrdU ${ }^{+}$cell, there is a BrdU ${ }^{-}$cell (arrowhead) coexpressing OMP (E1, blue) and AC3 (E3, red); $\mathbf{E 4}$ shows a merged image. Dashed white lines delineate the surface of the OE (top) and basal lamina (bottom). Scale bars: $\boldsymbol{A}, 25 \mu \mathrm{m} ; \boldsymbol{C}-\boldsymbol{E}, 10 \mu \mathrm{m}$

\section{Discussion}

Basal progenitor cells in the OE generate new OSNs throughout the life span of the mouse (for review, see Brann and Firestein, 2014). Although the dynamics of OE development and the targeting of OSN axons to the OB have been widely studied during early perinatal development, little was known of those events in the mature young adult. Here, we illustrate the dynamics of OSN neurogenesis and examine OSN behavior in a mature olfactory system. These data are fundamental to understanding the processes of adult neurogenesis and the incorporation of newly generated neurons into established circuits. Specifically, we provide critical information about the behavior of OSNs in adult stages that includes the following: the timeline of radial migration throughout the $\mathrm{OE}$, molecular maturation, and axonal extension toward the $\mathrm{OB}$, as summarized in Figure 11.

\section{Neurogenesis dynamics in the mature OE}

In this study, using P25 mice we demonstrate that the ventral septum harbors significantly more newborn

\section{A}
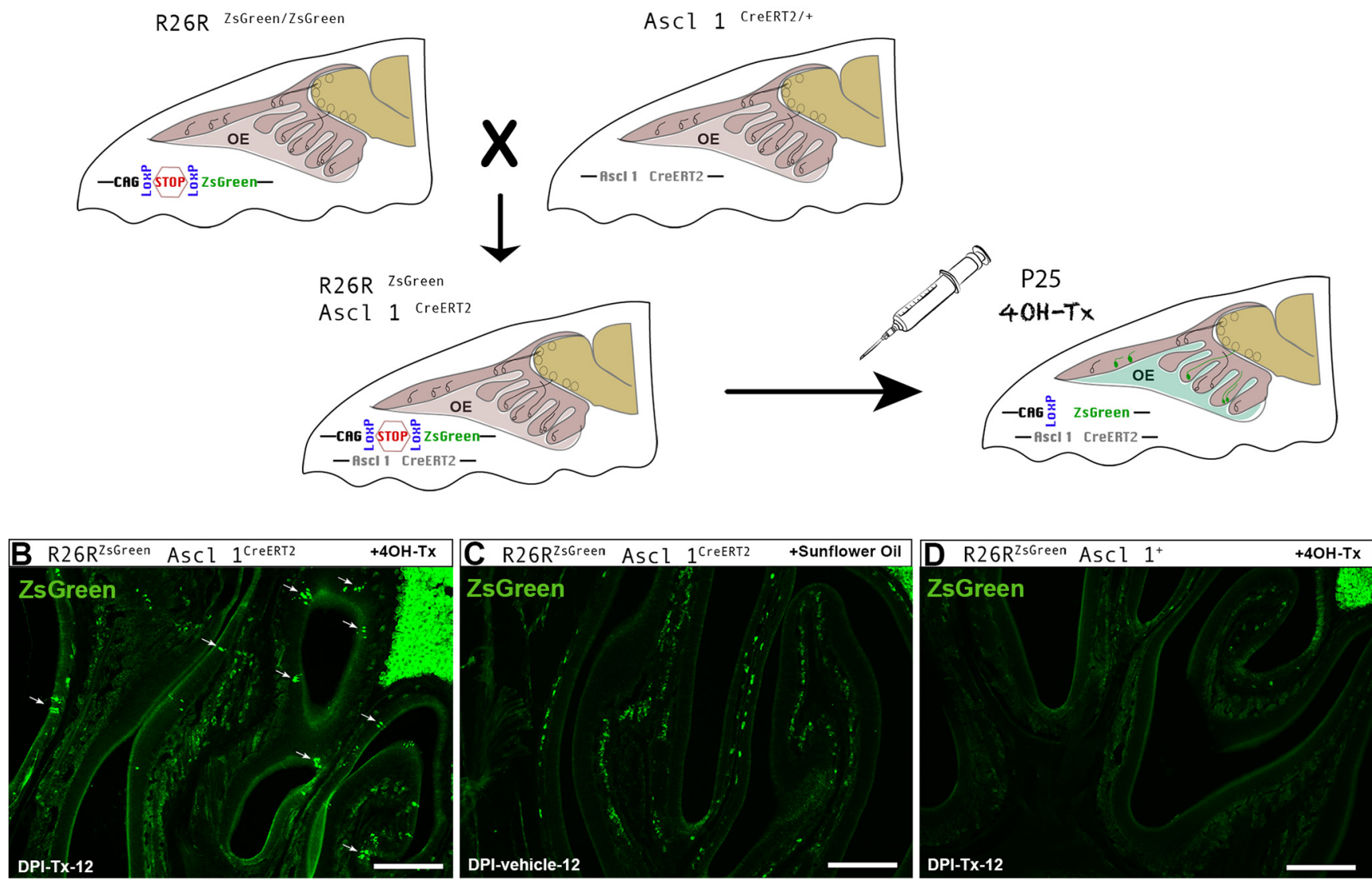

Figure 7. Inducible Cre-recombinase strategy for labeling P25-born OSNs in the OE following basal cell division. $\boldsymbol{A}$, Ascl1 ${ }^{\text {CreERT2/ }}$ R26R ZsGreen double transgenic mice were obtained by crossing an Ascl1 ${ }^{\text {CreERT2/+ }}$ transgenic mice line with an R26R ${ }^{Z s G r e e n / Z s G r e e n}$ transgenic mice line. 4OH-Tx induces Cre recombination in Ascl1 ${ }^{+}$cells, which results in the expression of ZsGreen in Ascl1 ${ }^{\text {CreERT2/ }}$ R26R ZsGreen double transgenic mice. $\boldsymbol{B}-\boldsymbol{D}$, Cre-recombinase strategy controls: Ascl1 CreERT2/R26R ${ }^{\text {ZsGreen }}$ double transgenic mice show olfactory sensory neuron-specific labeling $12 \mathrm{~d}$ after $4 \mathrm{OH}-\mathrm{Tx}$ injection $(\boldsymbol{B})$, but no specific labeling after sunflower oil injection, although some nonspecific labeling is present deep in the OE and beneath the basal lamina (C); Ascl $1^{+} / \mathrm{R}_{2} 6 \mathrm{R}^{\mathrm{ZsG} \text { (aen }}$ transgenic mice show no labeling after $4 \mathrm{OH}-\mathrm{Tx}$ injection $(\boldsymbol{D})$. Scale bars, $300 \mu \mathrm{m}$. 


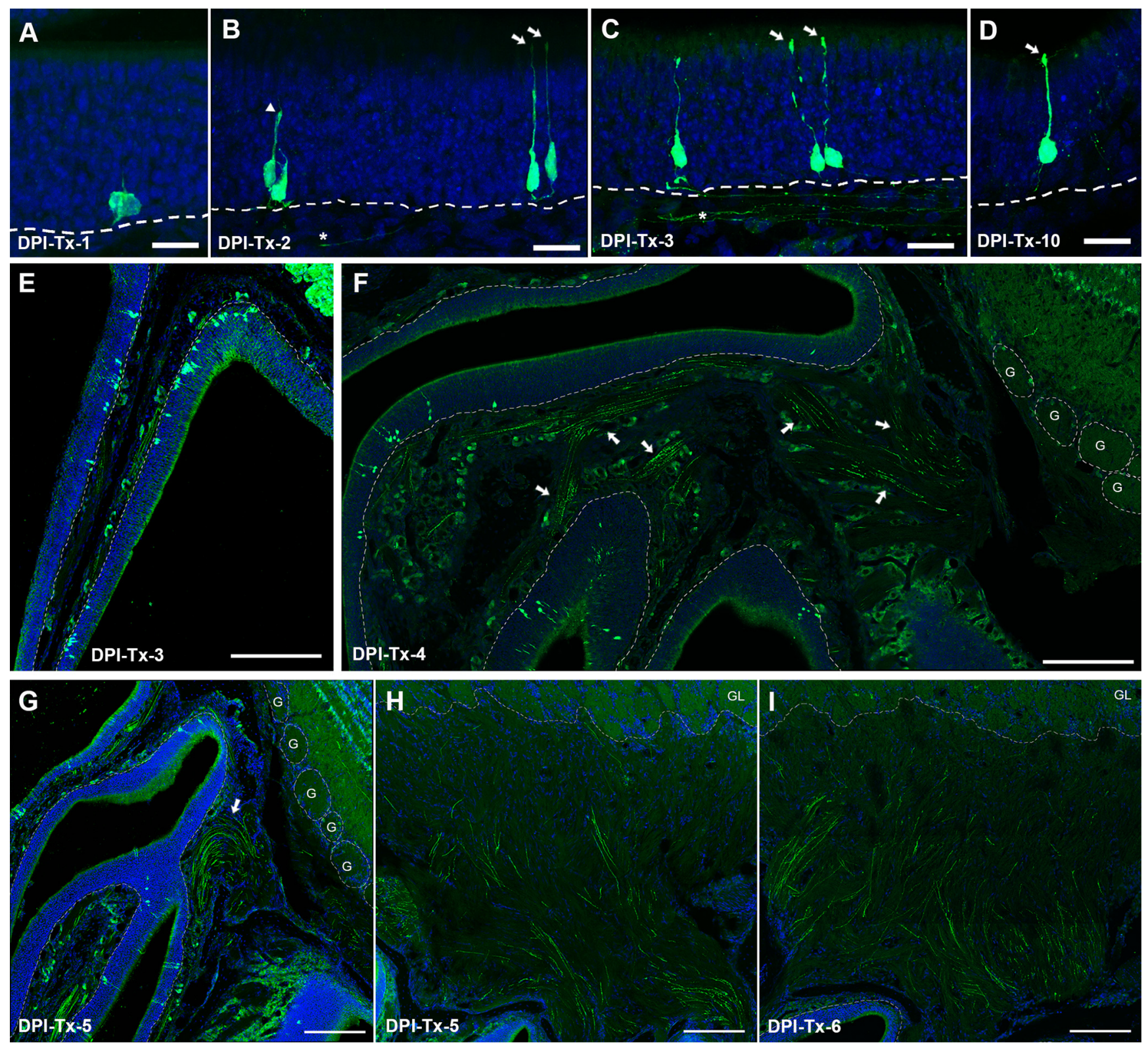

Figure 8. In vivo genetic fate-mapping strategy reveals spatiotemporal morphologic features of P25-born OSNs. $\boldsymbol{A}-\boldsymbol{D}, Z_{\text {ZsGeen }}{ }^{+}$cell bodies migrate radially toward the surface of the OE during a $12 \mathrm{~d}$ time course following basal cell division, revealing that most of them are differentiated as OSNs with characteristic morphologic features. OSN apical dendrites and axons can be detected as early as 2 d following $4 \mathrm{OH}-\mathrm{Tx}$ injection $(\boldsymbol{B}-\boldsymbol{D})$, but not earlier $(\boldsymbol{A})$. $\boldsymbol{E}-\boldsymbol{H}$, ZsGreen ${ }^{+}$axons form fascicles starting at $3 \mathrm{~d}$ following $4 \mathrm{OH}-\mathrm{Tx}$ injection $(\boldsymbol{E})$ and travel toward the OB $(\boldsymbol{F})$, and cross the cribriform plate at DPI-Tx-4/5 (G, arrow), and some of them reach the oONL as early as DPI-Tx-5 $(\boldsymbol{H})$. I, By DPI-Tx-6, the oONL is heavily innervated by ZsGreen ${ }^{+}$axons. DRAQ-5 is in blue. Dashed white lines delineate the basal lamina in $\boldsymbol{A}-\mathbf{G}$, and the limit between the glomerular layer (GL) and the ONL in $\boldsymbol{H}$. Dotted circles delineate glomeruli in $\boldsymbol{G}$, and each glomerulus is designated by the letter "G." Scale bars: $\boldsymbol{A}-\boldsymbol{D}, 20 \mu \mathrm{m} ; \boldsymbol{E}, \boldsymbol{F}, \boldsymbol{H}, \boldsymbol{I}, 200 \mu \mathrm{m} ; \boldsymbol{G}, 300 \mu \mathrm{m}$.

OSNs (approximately sixfold more) than the dorsal septum. This is consistent with our observation that the number of proliferative cells is higher in the ventral region compared with the dorsal region. Moreover, our data show that iOSNs in the ventral OE migrate faster through the OE (Fig. 4B). These results complement previous studies reporting a thinner layer of mOSNs in the ventrolateral zone IV of the OE, when compared with zone I (dorsal OE; Vedin et al., 2009). Given the higher proliferation rate and more rapid migration, our results are consistent with the hypothesis that OSNs generated in the ventral OE have a relatively shorter life span (Vedin et al., 2009).

Individual OSNs express only one OR gene, and each OR gene is confined to overlapping domains in the OE, which are summarized as zones (zones I, II, III, and IV). Thus, we cannot rule out that OSNs expressing different ORs undergo different proliferation rates. The ventral part of the septal wall that we analyzed corresponds to zones II and III, and the OSNs populating these zones 

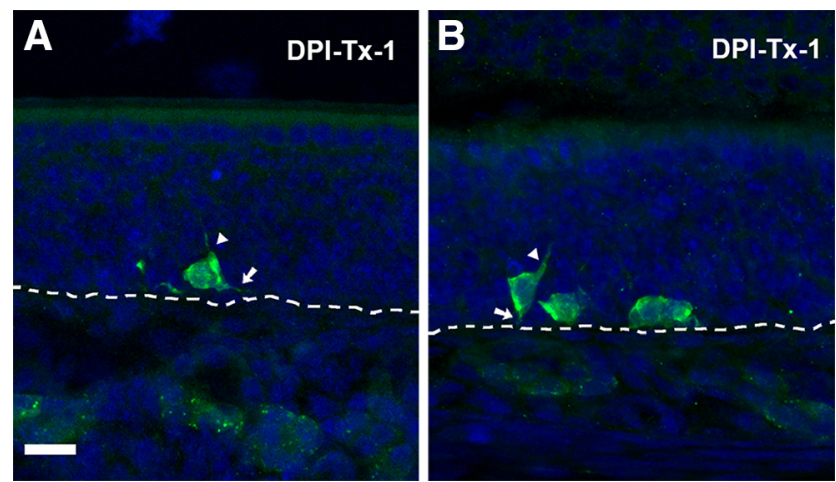

Figure 9. In vivo genetic fate-mapping strategy reveals no evidence of polarity in P25-born OSNs. A, B, ZsGreen ${ }^{+}$cell bodies lying on the basal lamina (dashed line) at DPI-Tx-1. Initial extension of the apical dendrite (arrowhead) and axon (arrow). Scale bar, $20 \mu \mathrm{m}$.

express predominately class II genes (Miyamichi et al., 2005). In contrast, the dorsal septum, which we analyzed here, is considered zone I, and is populated predominately by class I and some class II OR genes (Miyamichi et al., 2005). Collectively, these data suggest that the proliferation rate in the adult OE could be influenced by the OR expressed. A differential onset is also consistent with the findings of previous studies showing that the first expression and subsequent expansion of individual OR expression is unique (Rodriguez-Gil et al., 2010), and of recent studies that demonstrate differential OSN proliferation in dorsal versus ventral OE (Eerdunfu et al., 2017).

\section{Maturation of OSNs}

Our results suggest that a newborn OSN requires $>24$ $\mathrm{h}$ following cell division to differentiate into an iOSN, as measured by the onset of GAP 43 expression. This may reflect the time period necessary for progenitor cells to give rise to precursor cells (Neurogenin $1^{+}$, NeuroD $^{+}$). These precursor cells subsequently commit to a gene expression pattern that allows them to differentiate into the OSN (for review, see Suárez et al., 2012; Brann and Firestein, 2014). Previous studies reported that the presence of GAP 43 is transiently high in a temporal window between 3 and $9 \mathrm{~d}$ following injection of the thymidine analog EdU (Coleman et al., 2017), and between 5 and 10 d for Gy8 following basal cell division (Savya et al., 2019), both of which are markers for iOSNs. Our results are overall in agreement with these previous findings; we show that GAP 43 is first expressed at DPI-Tx-3, peaks at DPI-Tx-5, maintains high expression through DPI-Tx-10, and decreases significantly afterward.

GAP 43 is implicated in the regulation of actin dynamics in growth cones, axonal growth (Williams et al., 2016), and synaptic plasticity in adult neurons (Holtmaat et al., 1997). GAP 43 overexpression is associated with increased axonal growth (Aigner et al., 1995; Leu et al., 2010; Donnelly et al., 2011, 2013) and axon sprouting and regeneration after injury (Grasselli et al., 2011; Allegra Mascaro et al., 2013). Correspondingly, a lack of GAP 43 is related to defects in neuronal development and axonal guidance
(Strittmatter et al., 1995; Donovan et al., 2002; Shen et al., 2002; Mcllvain et al., 2003). These data suggest that GAP 43 plays a key role in neuronal plasticity and growth. We show that in the OE the number of GAP $43^{+}$OSNs remains high between 3 and $10 \mathrm{~d}$ following basal cell division. This time window of robust GAP 43 expression coincides with the extension process of their axons and navigation of the established olfactory nerve from the basal lamina of the $\mathrm{OE}$ to the $\mathrm{OB}$, as our fate-mapping strategy shows.

To understand the ongoing innervation of the $\mathrm{OB}$ by adult-born OSN axons in the young adult, we addressed the following question: do OSNs require a similar timeframe to mature and innervate the $\mathrm{OB}$ regardless of the stage of development of the olfactory system? We demonstrate that OMP is expressed at DPI-B-8 $(4.67 \%$ of $\mathrm{BrdU}^{+}$OSNs express OMP) in P25 mice. Our data are consistent with previous studies that used different approaches to label cells at the time of neurogenesis and analyze OMP expression in OSNs of different ages and, in some cases, following OE injury. In concordance with our data, these alternate approaches also found that OSNs do not express OMP before $6-7 \mathrm{~d}$ following basal cell division, regardless of the age of the animal or the OE condition (Miragall and Monti Graziadei, 1982; Schwob et al., 1992; Kondo et al., 2010; Kikuta et al., 2015; RodriguezGil et al., 2015; Savya et al., 2019). Our findings show that the number of $\mathrm{OMP}^{+}$cells increases significantly after $8 \mathrm{~d}$ following basal cell division (Table 2, Fig. 4E), which corresponds temporally with axons reaching the surface of the $\mathrm{OB}$ and initial innervation of the glomerular neuropil (Fig. 10C,D). Earlier studies suggested that OSN synaptogenesis begins at the time of glomerular innervation (Farbman and Margolis, 1980), which would then correlate with the downregulation of GAP 43 and the upregulation of OMP. Addressing this more comprehensively with birthdate labeling of axons would be a timely and a more effective assessment of this hypothesis.

Of interest, prior work (Coleman et al., 2017) found that the percentage of EdU ${ }^{+}$cells expressing OMP 5 d following EdU injections was slightly higher than what we observed in this work. The small discrepancy between our timelines may be accounted for by different quantitative analyses or animal housing conditions (Hinds et al., 1984; Mackay-Sim and Kittel, 1991; Holl, 2018). Moreover, as we report here and as others have noted (Vedin et al., 2009), the OE is a heterogeneous and asynchronous system with respect to neurogenesis and differentiation. Coleman et al. (2017) studied neurogenesis dynamics in areas containing OSNs expressing the olfactory receptor P2 (olfr17), while we included the entire septal OE. Although waves of proliferation or differentiation have not been described, we previously demonstrated that P2 is among the early-appearing ORs during embryonic development (Rodriguez-Gil et al., 2010), which is consistent with the notion that both the initial appearance and timeline to maturation may differ among subpopulations of OSNs.

AC3 expression is required for a canonical OSN to mature and reach the appropriate glomerulus, and to 

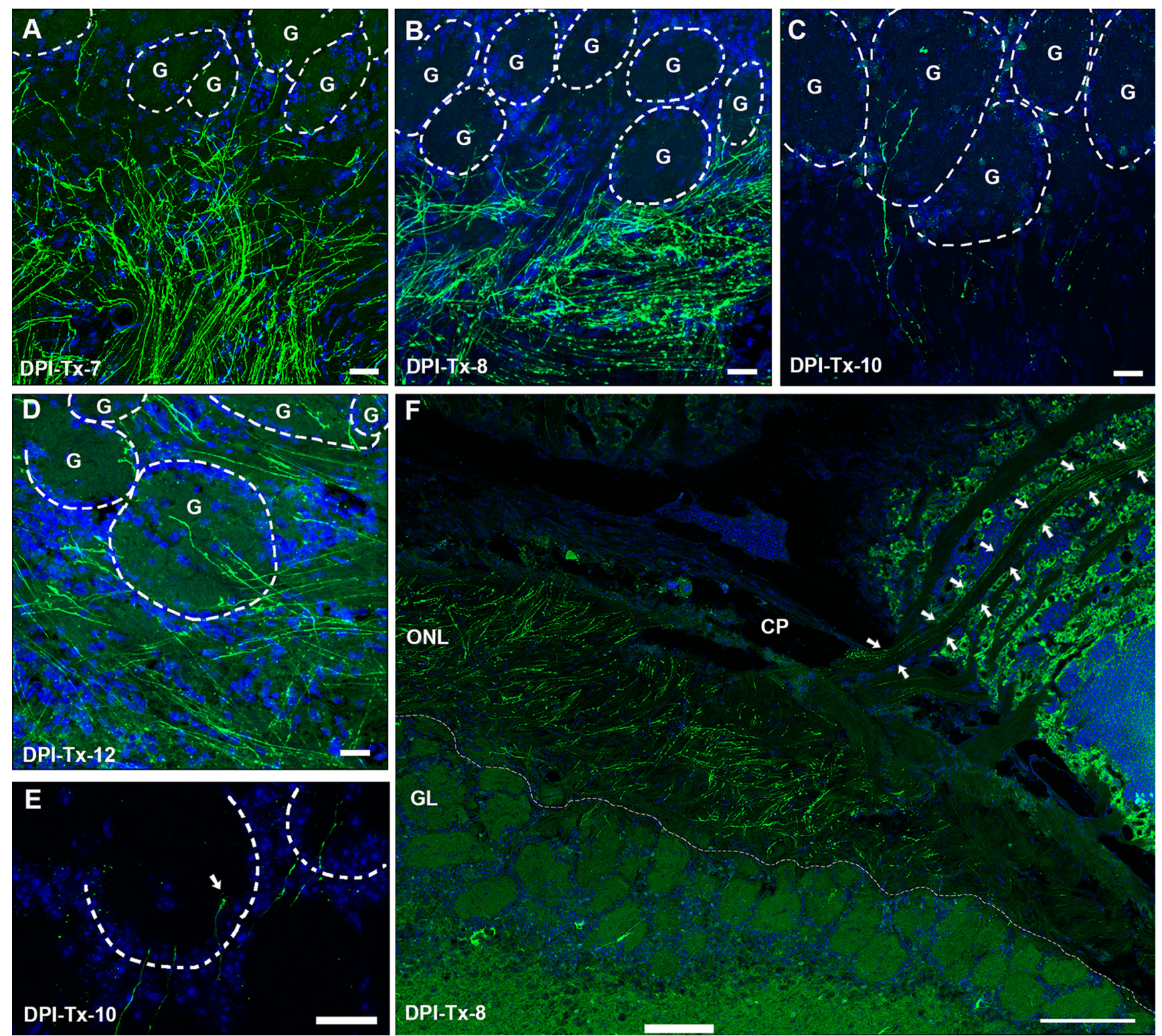

GL

CP

\section{DPI-T $x-8$}

Figure 10. Tracking ZsGreen ${ }^{+}$axon extension in Ascl1 ${ }^{\text {CreERT2}} / R_{2} 6 R^{Z s G r e e n}$ double transgenic mice at different time points following $4 \mathrm{OH}-\mathrm{Tx}$ injection. $\boldsymbol{A}, \boldsymbol{B}, \boldsymbol{F}, \mathrm{ZsGreen}^{+}$axons innervate iONL profoundly at 7-DPI-Tx $(\boldsymbol{A})$, and they surround ventral glomeruli closely at DPI-Tx-8; some scarce axons enter the GL $(\boldsymbol{B}, \boldsymbol{F})$. Panoramic sagittal view showing a ZsGreen ${ }^{+}$axon pathway (arrows) from the OE to the ventrolateral OB $(\boldsymbol{F}) . \boldsymbol{C}, \boldsymbol{D}$, Labeled axons unequivocally innervate glomerular neuropil by $10 \mathrm{~d}$ following basal cell division. $\boldsymbol{E}$, Detail of ZsGreen ${ }^{+}$axon growth cones (arrow) in the GL. DRAQ-5 is in blue. Dashed circles delineate glomeruli in $\boldsymbol{A}-\boldsymbol{D}$, and each glomerulus is designated by the letter "G." Dotted white lines delineate the limit between the GL and the ONL in $\boldsymbol{F}$. CP, Cribriform plate; GL, glomerular layer. Scale bars: $\boldsymbol{A}-\boldsymbol{D}, 25 \mu \mathrm{m} ; \boldsymbol{E}, 20 \mu \mathrm{m} ; \boldsymbol{F}, 200 \mu \mathrm{m}$.

establish functional synaptic contacts. Alterations of the AC3 expression and cAMP pathway disturb axon convergence and the accurate structural organization of glomeruli (Imai et al., 2006, 2009; Chesler et al., 2007; Zou et al., 2007; Maritan and Monaco, 2009; Miller et al., 2010). Moreover, a decrease in the number of specific glomeruli and a corresponding decrease in OMP have also been reported in AC3 knock-out mice (Col et al., 2007). Since the dynamic timing of AC3 expression may impact axon targeting, we wanted to determine when P25-born OSNs express AC3 and how its expression is related to OMP. We show for the first time that AC3 expression occurs early after basal cell division, at DPI$\mathrm{B}-3$, with a considerable increase $5 \mathrm{~d}$ later that is synchronous with the initial expression of OMP. Here we demonstrate that, similar to what was shown in perinatal stages (Rodriguez-Gil et al., 2015), AC3 expression precedes OMP. Moreover, at DPI-B-10 and DPI-B-12, we found that most of the $\mathrm{OMP}^{+}$adult-born OSNs are also $\mathrm{AC3}^{+}$(Fig. 6B,C4, dotted circle, 6D4, dotted circle). We did find a small group of $\mathrm{BrdU}^{+} / \mathrm{OMP}^{+}$OSNs that do not express AC3 (Fig. 6C4, dotted square, 6E4, arrow). It seems plausible that the small percentage of $\mathrm{OMP}^{+}$/ $\mathrm{AC3}^{-}$OSNs we reported here could belong to a subpop- 


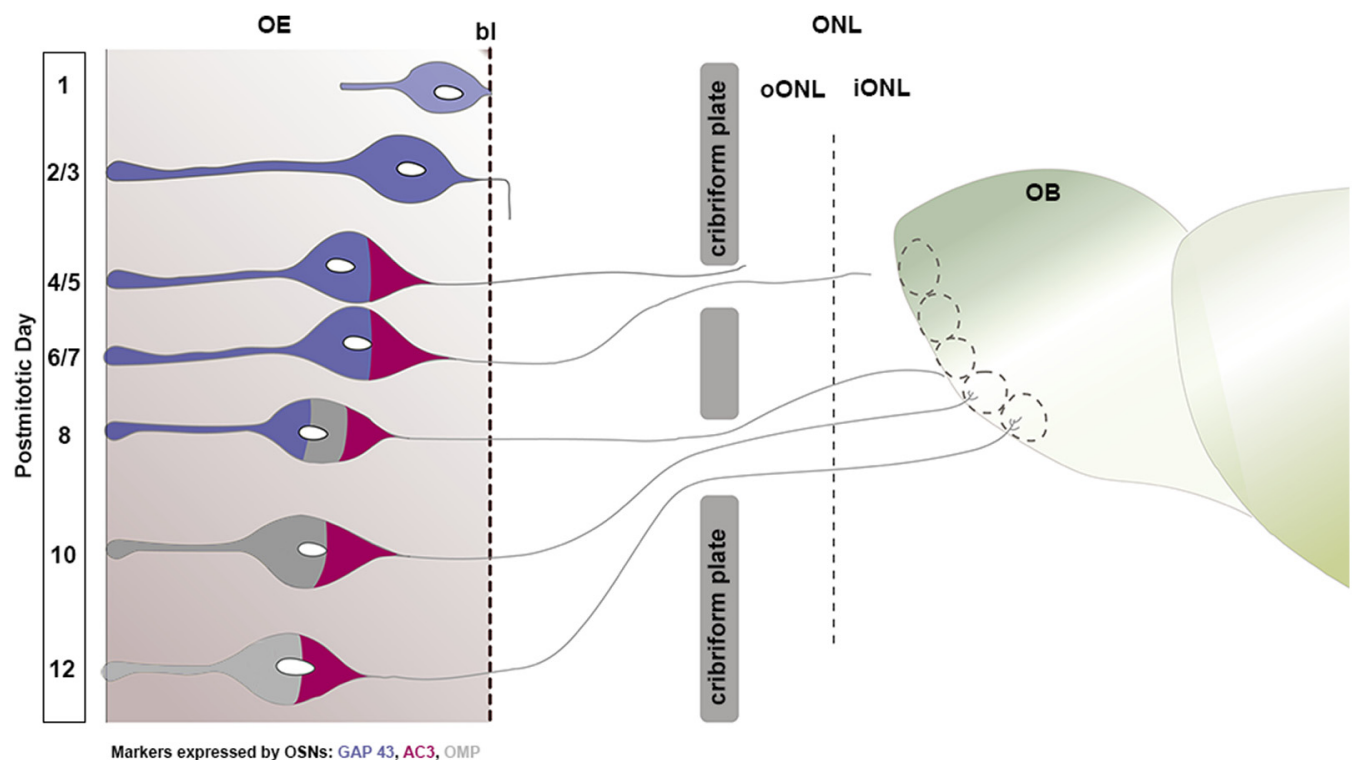

Figure 11. Schematic integrating three aspects of the OSN maturation process based on a compilation of postmitotic data following both the BrdU and 4OH-Tx protocols at P25: (1) cell body radial migration in the OE; (2) differential marker expression; and (3) axon extension from the OE to the OB. Cell morphology changes; expression of GAP 43 (blue), AC3 (maroon), and OMP (gray); and axonal extension progress are correlated with the corresponding postmitotic day. P25-born OSNs extend their apical dendrite and reach the OE surface 2/3 d following mitosis; simultaneously, they extend their axons deep in the basal lamina and express GAP 43; 4 and 5 $\mathrm{d}$ after basal cell division, axons cross the cribriform plate and reach the oONL, at which stage cells express AC3; 1/2 d later, axons innervate the oONL and iONL broadly. OSNs express OMP by postmitotic day 8 , and, concurrently, their axons reach the GL, ramifying themselves into the glomerular neuropil from day 10 following basal cell division onward. Black dashed line represents the basal lamina. bl, Basal lamina; GL, glomerular layer.

ulation of noncanonical OSNs (Trpc2 ${ }^{+}$type B; Omura and Mombaerts, 2014), although further studies are needed. Members of the transduction cascade, including cAMP, are key in axonal convergence and glomerular formation (Imai et al., 2006; Chesler et al., 2007; Mobley et al., 2010). Here we show that AC3 is upregulated beginning at DPIB-5 in young adult mice, when axons are located in the oONL before reaching the iONL. This suggests that AC3 expression might be critical for the final sorting of axons and convergence into the appropriate glomerulus.

The first evidence of differentiation among newborn cells in the OE was the onset of polarity that included the simultaneous extension of both an apical process, most likely fated to become the apical dendrite, and a basal process, most likely fated to become the axon. At later stages, growth cones were evident on both the apical and basal processes. The nascent apical dendrite extended rapidly, before the completion of the cell body radial migration to a central zone of the OE or the onset of OMP expression. The first dendritic knobs at the lumen of the OE were seen at $2 \mathrm{~d}$ following basal cell division. In some cases, rudimentary nascent cilia appear to be present but are not yet robustly expressed by $10 \mathrm{~d}$ following basal cell division (Fig. 8D). Prior work (Schwarzenbacher et al., 2005) describes cilia maturation during embryonic development, but the authors were not able to identify the ages of individual cells, as we did here. Their data show that, as it occurs for the maturation of different glomeruli, ORspecific populations exhibit different timing of ciliogenesis. However, they also demonstrated that as soon as ciliogenesis occurs, OR proteins appear to be relocated in the outgrowing cilia, and their presence decreases in the dendritic knob.

In summary, our data establish the following: (1) neurogenesis in the adolescent $\mathrm{OE}$ is regionally heterogeneous, with neurogenesis more robust in the ventral septum; (2) the radial migration of neuroblasts following basal cell division is regionally heterogeneous with neuroblast migration, which is more rapid in the ventral domain of the septum versus the dorsal domain; (3) the timeline of molecular maturation of OSNs (GAP $43>$ AC3 $>$ OMP) is similar to that seen in newborn mice; (4) following basal cell division, neuroblasts remain largely quiescent for $24 \mathrm{~h}$ until they begin to extend differentiating apical dendrites and basal axons; (5) within $48 \mathrm{~h}$, many OSNs exhibit dendrites that have begun to extend toward the lumen, most of which reach the lumen by $72 \mathrm{~h}$; (6) beginning at 48 $\mathrm{h}$, the new axons have crossed the basal lamina to join existing axon fascicles; (7) the OSN axons cross the cribriform plate by $4 \mathrm{~d}$ post-tamoxifen injection and begin to course along the surface of the OB; and (8) the initial approach to innervate glomeruli is evident at 8-10 d post-tamoxifen injection, with axons within the glomerular neuropil by $10 \mathrm{~d}$. These data provide an important new perspective on the maturation and incorporation of adultborn neurons into neural circuits and the ability of these cells to navigate previously established complex neuropil. We conclude that in young-adult stages, OSN molecular maturation and axon extension grossly recapitulate the mechanisms observed in the perinatal stages with a slightly different rhythm. 


\section{References}

Aigner L, Arber S, Kapfhammer JP, Laux T, Schneider C, Botteri F, Brenner HR, Caroni P (1995) Overexpression of the neural growthassociated protein GAP-43 induces nerve sprouting in the adult nervous system of transgenic mice. Cell 83:269-278.

Allegra Mascaro AL, Cesare P, Sacconi L, Grasselli G, Mandolesi G, Maco B, Knott GW, Huang L, De Paola V, Strata P, Pavone FS (2013) In vivo single branch axotomy induces GAP-43-dependent sprouting and synaptic remodeling in cerebellar cortex. Proc Natl Acad Sci U S A 110:10824-10829.

Brann JH, Firestein SJ (2014) A lifetime of neurogenesis in the olfactory system. Front Neurosci 8:353-374.

Bressel OC, Khan M, Mombaerts P (2016) Linear correlation between the number of olfactory sensory neurons expressing a given mouse odorant receptor gene and the total volume of the corresponding glomeruli in the olfactory bulb. J Comp Neurol 524:199209.

Chesler AT, Zou D-J, Le Pichon CE, Peterlin ZA, Matthews GA, Pei X, Miller MC, Firestein S (2007) A G protein/cAMP signal cascade is required for axonal convergence into olfactory glomeruli. Proc Natl Acad Sci U S A 104:1039-1044.

Cheung MC, Jang W, Schwob JE, Wachowiak M (2014) Functional recovery of odor representations in regenerated sensory inputs to the olfactory bulb. Front Neural Circuits 7:207.

Col JAD, Matsuo T, Storm DR, Rodriguez I (2007) Adenylyl cyclasedependent axonal targeting in the olfactory system. Development 134:2481-2489.

Coleman JH, Lin B, Schwob JE (2017) Dissecting LSD1-dependent neuronal maturation in the olfactory epithelium. J Comp Neurol 525:3391-3413.

Donnelly CJ, Willis DE, Xu M, Tep C, Jiang C, Yoo S, Schanen NC, Kirn-Safran CB, Van Minnen J, English A, Yoon SO, Bassell GJ, Twiss JL (2011) Limited availability of ZBP1 restricts axonal mRNA localization and nerve regeneration capacity. EMBO J 30:46654677.

Donnelly CJ, Park M, Spillane M, Yoo S, Pacheco A, Gomes C, Vuppalanchi D, McDonald M, Kim HH, Merianda TT, Gallo G, Twiss JL (2013) Axonally synthesized -actin and GAP-43 proteins support distinct modes of axonal growth. J Neurosci 33:33113322.

Donovan SL, Mamounas L. a, Andrews AM, Blue ME, McCasland JS (2002) GAP-43 is critical for normal development of the serotonergic innervation in forebrain. J Neurosci 22:3543-3552.

Eerdunfu, Ihara N, Ligao B, Ikegaya Y, Takeuchi H (2017) Differential timing of neurogenesis underlies dorsal-ventral topographic projection of olfactory sensory neurons. Neural Dev 12:2.

Farbman Al, Margolis FL (1980) Olfactory marker protein during ontogeny: immunohistochemical localization. Dev Biol 74:205215.

Grasselli G, Mandolesi G, Strata P, Cesare P (2011) Impaired sprouting and Axonal Atrophy in cerebellar climbing fibres following in vivo silencing of the growth-associated protein GAP-43. PLoS One 6:e20791.

Graziadei PP, Graziadei GA (1979) Neurogenesis and neuron regeneration in the olfactory system of mammals. I. Morphological aspects of differentiation and structural organization of the olfactory sensory neurons. J Neurocytol 8:1-18.

Graziadei PP, Monti Graziadei GA (1985) Neurogenesis and plasticity of the olfactory sensory neurons. Ann N Y Acad Sci 457:127-142.

Hinds JW, Hinds PL, McNelly NA (1984) An autoradiographic study of the mouse olfactory epithelium: evidence for long-lived receptors. Anat Rec 210:375-383.

Holl AM (2018) Survival of mature mouse olfactory sensory neurons labeled genetically perinatally. Mol Cell Neurosci 88:258-269.

Holtmaat AJ, Hermens WT, Sonnemans MA, Giger RJ, Van Leeuwen FW, Kaplitt MG, Oestreicher AB, Gispen WH, Verhaagen J (1997) Adenoviral vector-mediated expression of B-50/GAP-43 induces alterations in the membrane organization of olfactory axon terminals in vivo. J Neurosci 17:6575-6586.
Imai T, Suzuki M, Sakano H (2006) Odorant receptor-derived cAMP signals direct axonal targeting. Science 314:657-661.

Imai T, Yamazaki T, Kobayakawa R, Kobayakawa K, Abe T, Suzuki M, Sakano H (2009) Pre-target axon sorting establishes the neural map topography. Science 325:585-590.

Iwema CL, Fang H, Kurtz DB, Youngentob SL, Schwob JE (2004) Odorant receptor expression patterns are restored in lesionrecovered rat olfactory epithelium. J Neurosci 24:356-369.

Kawagishi K, Ando M, Yokouchi K, Sumitomo N, Karasawa M, Fukushima N, Moriizumi T (2014) Stereological quantification of olfactory receptor neurons in mice. Neuroscience 272:29-33.

Kikuta S, Sakamoto T, Nagayama S, Kanaya K, Kinoshita M, Kondo K, Tsunoda K, Mori K, Yamasoba T (2015) Sensory deprivation disrupts homeostatic regeneration of newly generated olfactory sensory neurons after injury in adult mice. J Neurosci 35:26572673.

Kim EJ, Ables JL, Dickel LK, Eisch AJ, Johnson JE (2011) Ascl1 (Mash1) defines cells with long-term neurogenic potential in subgranular and subventricular zones in adult mouse brain. PLoS One 6:e18472

Kondo K, Suzukawa K, Sakamoto T, Watanabe K, Kanaya K, Ushio M, Yamaguchi T, Nibu K, Kaga K, Yamasoba T (2010) Age-related changes in cell dynamics of the postnatal mouse olfactory neuroepithelium: cell proliferation, neuronal differentiation, and cell death. J Comp Neurol 518:1962-1975.

Leu B, Koch E, Schmidt JT (2010) GAP43 phosphorylation is critical for growth and branching of retinotectal arbors in zebrafish. Dev Neurobiol 70:897-911.

Lyons DB, Allen WE, Goh T, Tsai L, Barnea G, Lomvardas S (2013) An epigenetic trap stabilizes singular olfactory receptor expression. Cell 154:325-336.

Mackay-Sim A, Kittel P (1991) Cell dynamics in the adult mouse olfactory epithelium: a quantitative autoradiographic study. J Neurosci 11:979-984.

Maritan M, Monaco G (2009) Odorant receptors at the growth cone are coupled to localized cAMP and $\mathrm{Ca} 2+$ increases. Proc Natl Acad Sci U S A 106:3537-3542.

Mazzotti G, Gobbi P, Manzoli L, Falconi M (1998) Nuclear morphology during the S phase. Microsc Res Tech 40:418-431.

Mcllvain VA, Robertson DR, Maimone MM, McCasland JS (2003) Abnormal thalamocortical pathfinding and terminal arbors lead to enlarged barrels in neonatal GAP-43 heterozygous mice. J Comp Neurol 462:252-264.

Miller AM, Maurer LR, Zou DJ, Firestein S, Greer CA (2010) Axon fasciculation in the developing olfactory nerve. Neural Dev 5:20.

Miragall F, Monti Graziadei GA (1982) Experimental studies on the olfactory marker protein. II. Appearance of the olfactory marker protein during differentiation of the olfactory sensory neurons of mouse: an immunohistochemical and autoradiographic study. Brain Res 239:245-250.

Miyamichi K, Serizawa S, Kimura HM, Sakano H (2005) Continuous and overlapping expression domains of odorant receptor genes in the olfactory epithelium determine the dorsal/ventral positioning of glomeruli in the olfactory bulb. J Neurosci 25:3586-3592.

Mobley AS, Miller AM, Araneda RC, Maurer LR, Müller F, Greer CA (2010) Hyperpolarization-activated cyclic nucleotide-gated channels in olfactory sensory neurons regulate axon extension and glomerular formation. J Neurosci 30:16498-16508.

Monahan K, Lomvardas S (2015) Monoallelic expression of olfactory receptors. Annu Rev Cell Dev Biol 31:721-740.

Monti Graziadei GA, Karlan MS, Bernstein JJ, Graziadei PP (1980) Reinnervation of the olfactory bulb after section of the olfactory nerve in monkey (Saimiri sciureus). Brain Res 189:343-354.

Muñoz-Velasco I, Ortíz R, Echeverría OM, Escobar ML, Vázquez-Nin GH (2013) Characterization of the pre-meiotic S phase through incorporation of BrdU during spermatogenesis in the rat. $\mathrm{J}$ Histochem Cytochem 61:680-689.

Omura M, Mombaerts P (2014) Trpc2-expressing sensory neurons in the main olfactory epithelium of the mouse. Cell Rep 8:583-595. 
Ressler KJ, Sullivan SL, Buck LB (1993) A zonal organization of odorant receptor gene expression in the olfactory epithelium. Cell 73:597-609.

Richard MB, Taylor SR, Greer CA (2010) Age-induced disruption of selective olfactory bulb synaptic circuits. Proc Natl Acad Sci U S A 107:15613-15618.

Rodriguez-Gil DJ, Treloar HB, Zhang X, Miller AM, Two A, Iwema C, Firestein SJ, Greer CA (2010) Chromosomal location-dependent nonstochastic onset of odor receptor expression. J Neurosci 30: 10067-10075.

Rodriguez-Gil DJ, Bartel DL, Jaspers AW, Mobley AS, Imamura F, Greer CA (2015) Odorant receptors regulate the final glomerular coalescence of olfactory sensory neuron axons. Proc Natl Acad Sci U S A 112:5821-5826.

Savya SP, Kunkhyen T, Cheetham CEJ (2019) Low survival rate of young adult-born olfactory sensory neurons in the undamaged mouse olfactory epithelium. J Bioenerg Biomembr 51:41-51.

Schwarzenbacher K, Fleischer J, Breer H (2005) Formation and maturation of olfactory cilia monitored by odorant receptorspecific antibodies. Histochem Cell Biol 123:419-28.

Schwob JE (2002) Neural regeneration and the peripheral olfactory system. Anat Rec 269:33-49.

Schwob JE, Szumowski KE, Stasky AA (1992) Olfactory sensory neurons are trophically dependent on the olfactory bulb for their prolonged survival. J Neurosci 12:3896-3919.

Schwob JE, Jang W, Holbrook EH, Lin B, Herrick DB, Peterson JN, Hewitt Coleman J (2017) Stem and progenitor cells of the mammalian olfactory epithelium: taking poietic license. J Comp Neurol 525:1034-1054.

Shen Y, Mani S, Donovan SL, Schwob JE, Meiri KF (2002) Growthassociated protein-43 is required for commissural axon guidance in the developing vertebrate nervous system. J Neurosci 22:239-247.

Sokpor G, Abbas E, Rosenbusch J, Staiger JF, Tuoc T (2018) Transcriptional and epigenetic control of mammalian olfactory epithelium development. Mol Neurobiol 55:8306-8327.

Strittmatter SM, Fankhauser C, Huang PL, Mashimo H, Fishman MC (1995) Neuronal pathfinding is abnormal in mice lacking the neuronal growth cone protein GAP-43. Cell 80:445-452.
Suárez R, García-González D, de Castro F (2012) Mutual influences between the main olfactory and vomeronasal systems in development and evolution. Front Neuroanat 6:1-14.

Sullivan SL, Adamson MC, Ressler KJ, Kozak CA, Buck LB (1996) The chromosomal distribution of mouse odorant receptor genes. Proc Natl Acad Sci U S A 93:884-888.

Suzuki Y, Takeda M (1993) Basal cells in the mouse olfactory epithelium during development: immunohistochemical and electronmicroscopic studies. Brain Res Dev Brain Res 73:107-113.

Treloar HB, Feinstein P, Mombaerts P, Greer CA (2002) Specificity of glomerular targeting by olfactory sensory axons. J Neurosci 22: 2469-2477.

Trinh K, Storm DR (2003) Vomeronasal organ detects odorants in absence of signaling through main olfactory epithelium. Nat Neurosci 6:519-525.

Ueha R, Shichino S, Ueha S, Kondo K, Kikuta S, Nishijima H, Matsushima K, Yamasoba T (2018) Reduction of proliferating olfactory cells and low expression of extracellular matrix genes are hallmarks of the aged olfactory mucosa. Front Aging Neurosci $10: 86$.

Vassar R, Ngai J, Axel R (1993) Spatial segregation of odorant receptor expression in the mammalian olfactory epithelium. Cell 74:309-318.

Vedin V, Molander M, Bohm S, Berghard A (2009) Regional differences in olfactory epithelial homeostasis in the adult mouse. $J$ Comp Neurol 513:375-384.

Williams KR, McAninch DS, Stefanovic S, Xing L, Allen M, Li W, Feng Y, Mihailescu MR, Bassell GJ (2016) hnRNP-Q1 represses nascent axon growth in cortical neurons by inhibiting Gap-43 mRNA translation. Mol Biol Cell 27:518-534.

Zhang Z, Yang D, Zhang M, Zhu N, Zhou Y, Storm DR, Wang Z (2017) Deletion of type 3 adenylyl cyclase perturbs the postnatal maturation of olfactory sensory neurons and olfactory cilium ultrastructure in mice. Front Cell Neurosci 11:1.

Zou DJ, Chesler AT, Le Pichon CE, Kuznetsov A, Pei X, Hwang EL, Firestein S (2007) Absence of adenylyl cyclase 3 perturbs peripheral olfactory projections in mice. J Neurosci 27:6675-6683. 